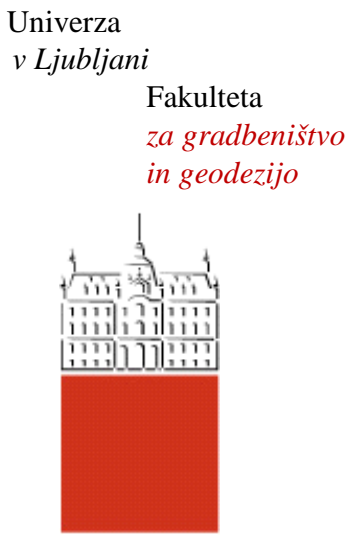

Jamova cesta 2

1000 Ljubljana, Slovenija

http://www3.fgg.uni-lj.si/

DRUGG - Digitalni repozitorij UL FGG http://drugg.fgg.uni-lj.si/

Ta članek je avtorjeva zadnja recenzirana različica, kot je bila sprejeta po opravljeni recenziji.

Prosimo, da se pri navajanju sklicujte na bibliografske podatke, kot je navedeno:
University
of Ljubljana

Faculty of

Civil and Geodetic

Engineering

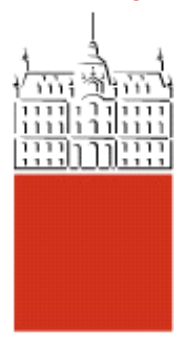

Jamova cesta 2

SI - 1000 Ljubljana, Slovenia

http://www3.fgg.uni-lj.si/en/

DRUGG - The Digital Repository http://drugg.fgg.uni-lj.si/

This version of the article is author's manuscript as accepted for publishing after the review process.

When citing, please refer to the publisher's bibliographic information as follows:

Trtnik G., Valič M. I., Turk G. 2013. Measurement of setting process of cement pastes using non-destructive ultrasonic shear wave reflection technique. NDT \& E International 56:65-75. doi: 10.1016/j.ndteint.2013.02.004. 


\title{
Measurement of setting process of cement pastes using non-destructive ultrasonic shear wave reflection technique
}

\author{
Gregor Trtnik ${ }^{1, *}$, Marko I. Valičㄹ, Goran Turk ${ }^{3}$
}

1 IGMAT Building materials institute, Polje 351c, 1000 Ljubljana, Slovenia; e-mail: grega.trtnik@igmat.eu

${ }^{2}$ University of Ljubljana, Faculty of Maritime and Transport Studies, Pot Pomorščakov 4, 6320 Portorož, Slovenia; e-mail: marko.valic@fpp.uni-lj.si

${ }^{3}$ University of Ljubljana, Faculty of Civil and Geodetic Engineering, Jamova 2, 1000 Ljubljana, Slovenia; e-mail: goran.turk@fgg.uni-lj.si

\begin{abstract}
In the paper a new setup for measuring setting and hardening process of cementitious materials, using a non-destructive ultrasonic shear wave reflection technique and designed with the objective to be easily used in-situ, is described. Using the developed setup, the measurements can be performed by slight deepening of a measuring head into a paste in a mold or by placing the paste into a mold fixed on a measuring head. To test the proposed methodology, cement pastes with different compositions were prepared and exposed to different curing temperatures. Significant differences in the evolution of a change of a shear wave reflection coefficient $\Delta r$ in time were observed, indicating ability of the method to monitor setting process of cement pastes. Moreover, some interesting phenomena in the solidification process of the materials can be identified. A linear relationship between development of the $\Delta r$ and penetration resistance $d_{\mathrm{P}}$ values in time was found, allowing development of a simplified procedure to determine both initial and final setting times of the material.
\end{abstract}

Keywords: Cement paste, Ultrasonics, Shear wave, Setting, Wave reflection method.

\section{INTRODUCTION}

On a large construction site, it is often difficult to estimate properties of cement based materials accurately due to differences in curing conditions between a lab and construction site. Among these, setting times are usually considered as the most important properties of early age cement based materials. Development of a suitable, reliable, and easy manageable non-destructive testing (NDT) method which enables continuous monitoring of the early age hydration and formation of structure process, including initial and final setting times, is therefore of considerable importance.

Advances in measurement and computer technology during recent years have allowed the development of many advanced methods to monitor the setting and hardening process of cement based materials. Among others, different ultrasonic (US) methods turned out to be very effective and reliable in evaluating microstructural changes during the early age hydration process of various cementitious materials, including ultra-high performance materials [1]. Due to unambiguous importance of both the initial $\left(t_{\mathrm{I}}\right)$ and final $\left(t_{\mathrm{F}}\right)$ setting times, a comprehensive research has been performed to estimate these essential characteristics with the use of the US methods. Using US wave transmission (USWT) technique, some procedures have been developed to identify the initial setting time based on various P-wave velocity threshold values [2-6]. Alternatively, certain features on the US P-wave velocity curves can be used to estimate the initial setting time, namely the first inflection point [5-8], the time when the P-wave velocity reaches velocity in water [5,6], the time when P-wave velocity starts to increase [9], or the intersection of three straight lines tangent to the P-wave velocity curve [10].

\footnotetext{
${ }^{*}$ Corresponding author. Phone: +386 158626 30; fax: +386 15862601

Email: grega.trtnik@igmat.eu
} 
Usually, USWT method can only be performed by accessing two sides of the specimen which often limits its practical application. To overcome this inconvenience, US wave reflection (USWR) method has been developed which requires one contacting surface. The technique was first applied to cementitious materials by Stepišnik et al. [11] and was extended further by Valič [12]. During the last decade, many studies have been performed to analyze the possibility of using this NDT US technique to describe setting and hardening behavior of different cementitious materials. Relationships between a shear wave reflection coefficient $r(-)$ or a reflection loss $R L(-)$ and the parameters which control properties of cementitious materials have been established. Correlation between a change of the reflection coefficient $\Delta r$ and compressive and bending strength was reported by Valič and Vuk [13] and strong linear relation between $R L$ and degree of hydration was found $[14,15]$. However, this relationship is not unique and is influenced by water/cement ratio. On the contrary, unique linear relationship was found between $R L$ and decrease of capillary porosity [14] and $R L$ and compressive strength [16]. Moreover, numerical simulations have shown that the development of $R L$ is closely related to the development of some parameters that describe microstructural evolution of cementitious materials. Using HYMOSTRUC3D model [17,18], unambiguous relation between $R L$ and specific contact area of solid phase was established [16].

Due to the practical usefulness of the USWR method, studies have been performed to determine the initial and final setting times using this NDT US technique. According to the original research performed by Valič et al. [19], both $t_{\mathrm{I}}$ and $t_{\mathrm{F}}$ times were found to appear at the same level of $\Delta r$, independently of w/c ratio changing from $0.25-0.30$. Sun et al. $[14,16]$ performed a similar study on three cement pastes with w/c ratios equal to $0.35,0.50$, and 0.60 and suggested to define a specific value of $R L$ within a certain interval of probability to indicate the occurrence of the initial setting regardless of w/c ratio. On the contrary, they indicated that final setting can not be defined by using a specific value of $R L$. According to Voigt et al. [20] a consistent relationship between $t_{\mathrm{I}}$ and the point at which the $R L-t$ curve starts to increase could be identified. Using L-wave pulse reflection technique, Ozturk et al. [21] indicated that $t_{\mathrm{I}}$ and $t_{\mathrm{F}}$ setting times coincide with the time of the first inflection point on the curve representing the development of the shear wave reflection coefficient $W R F$ in time and the time when the WRF - $t$ curve starts to increase after having reached its minimum, respectively. Chung [22] found out that the initial set occurs later than the onset of stiffening of the material, indicated by a rapid change in the slope of the $\Delta r$ $-t$ curves [23].

These results indicate the ability of USWR method to monitor the setting behavior of cement-based materials. However, since a very limited number of parameters which influence hydration kinetics have been used in previous studies [14, 16, 19-21], additional experiments are necessary to analyze the possibility of using USWR method to estimate both $t_{\mathrm{I}}$ and $t_{\mathrm{F}}$ times in more detail. Consequently, relationship between the setting times and USWR method is worthy of further investigation [16].

For this purpose, a comprehensive experimental work was performed with the results presented in this article. A new USWR apparatus was developed aimed to develop an instrument which can be easily and effectively used in-situ. Evolution of the change of the shear wave reflection coefficient $\Delta r$ and penetration resistance $d_{\mathrm{P}}$ with time were measured simultaneously on twenty cement pastes with various compositions and exposed to different curing temperatures to get a relevant and appropriate relationship between these two characteristic parameters. The influence of water/cement ratio (w/c), ambient temperature $\left(T_{\mathrm{A}}\right)$, cement type, cement fineness (BS), and amount of $\mathrm{C}_{3} \mathrm{~A}$ on the $\Delta r-d_{\mathrm{P}}$ relationship was studied. On the basis of these results, a simplified procedure to determine both initial and final setting times is presented.

\section{EXPERIMENTAL MATERIALS AND METHODS}

\subsection{Experimental methods}

\subsubsection{Ultrasonic Wave Reflection Method}

A basic model of an apparatus using pulse USWR method has been already described by Valič [12]. However, during the recent years, several ideas for improvements came out with the objective to develop an instrument which can be easily and effectively used in-situ. As a result, a new apparatus USWR-4 
Hardening meter was constructed in a multi-head version with four measuring heads operating simultaneously, allowing the measurements to be performed at four different locations.

A detailed description of the principles of operation and performance of the apparatus is beyond the scope of this paper and can be found in [12]. However, some basic description is necessary to properly track the focus of the article. The USWR-4 Hardening meter is shown in Fig. 1 and consists of a main frame box with transmitter/receiver electronics, A/D converter board and power supply, measuring heads, and PC computer with suitable software. Measuring heads are of rugged construction and consist of a cylindrical aluminum body $(\Phi=30 \mathrm{~mm}, l=40 \mathrm{~mm})$ in which a very pure fused quartz rod of rectangular crosssection ( $a=10 \mathrm{~mm}, b=16 \mathrm{~mm}$ ) and length $l=50 \mathrm{~mm}$ is rigidly fastened. On the bottom end a PZE ultrasound transducer, acting as a transmitter and receiver, is hard bonded. A typical measuring sensor is shown in Fig. 1a. On the top end, with a measuring surface of $2 \mathrm{~cm}^{2}$, the sample to be tested is smeared (Fig. 1b) which can be easily performed at laboratory conditions. Alternatively, the quartz rods can be simply pushed into the sample (Fig. 1c) or installed on the surface of the concrete element, allowing the measurements to be performed in-situ.

a)

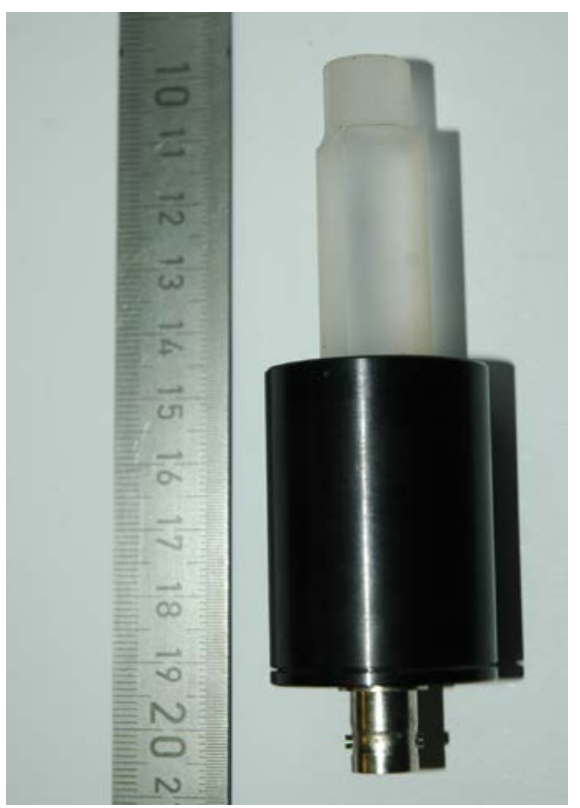

b)

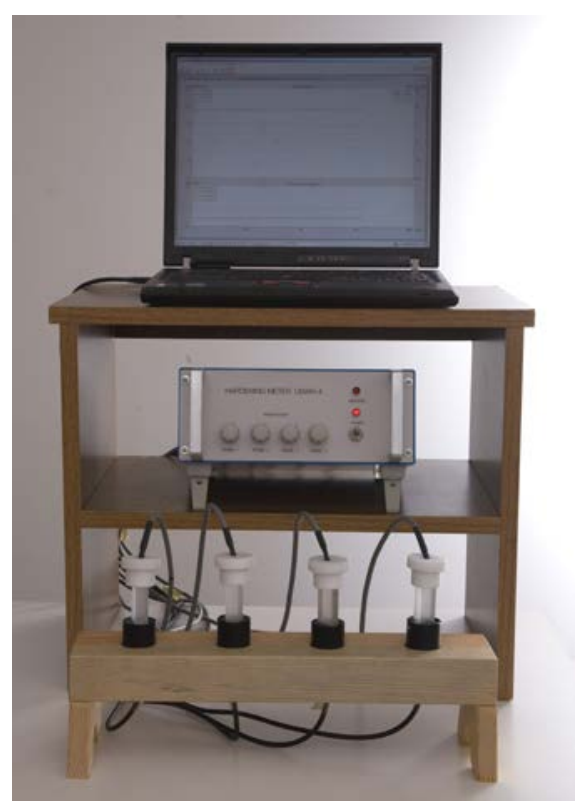

c)

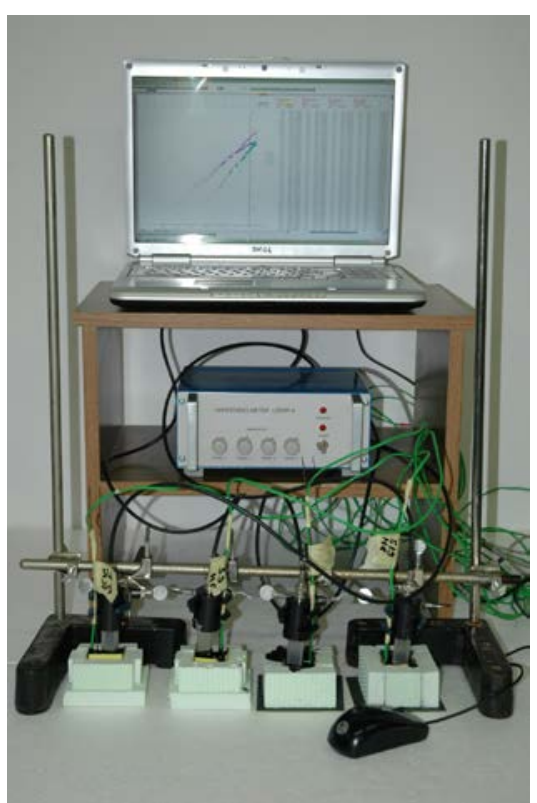

Fig. 1. USWR 4-Hardening meter with four measuring heads operating simultaneously; a) typical measuring sensor, b) possibility of laboratory application, c) possibility of in-situ application.

The principle of the USWR method consists of monitoring a dimensionless shear wave reflection coefficient $r$ at the interface formed by a quartz buffer material and the cement paste. Quartz has smaller acoustic impedance than steel resulting in a wider range in that the $r$ changes [24]. The measuring head is brought in contact with the cement paste immediately after mixing. As a result of the hydration process, hydration products develop, resulting in a larger amount of a solid phase in the structure of the material. Consequently, US wave propagation characteristics of the material are changing continuously, resulting in a variation of $r$ obtained from the amplitudes of successive reflections received from the buffer/cement paste interface in real time. As the time progresses, the amplitude of the first echo remains constant while the amplitudes of higher order echoes are changing constantly, resulting into echoes with smaller amplitudes and consequently lower values of the shear wave reflection coefficient $r$. The shear wave reflection coefficient $r$ is obtained by measuring $s_{1}$ and $s_{2}$ back echo amplitudes with a preset amount of signal averaging prior being digitalized and sent to PC computer, resulting into relatively smooth $r-t$ curves. The signals are obtained with a repetition rate of $1 \mathrm{~ms}$. A detailed theoretical description of the $r$ determination can be found in [12]. In this study, the change of the reflection coefficient $\Delta r$ (i.e. $\Delta r=1-r$ ) will be used in presenting the reflection coefficient data, which is increasing with the continuing hydration process [12]. 


\subsubsection{Vicat method}

As a supplementary method standard Vicat Needle tests according to European EN 196-3 standard were performed on all cement paste mixtures simultaneously to the USWR measurements. The method is based on measuring depth of penetration $d_{\mathrm{P}}$ ' of a steel cylinder needle into the cement paste. The penetration tests were performed at regular time intervals until the cement paste was completely set, resulting into a $d_{\mathrm{P}}-t$ diagram for each cement paste mixture, where $d_{\mathrm{P}}$ represents the distance between the needle and the base plate (i.e. $d_{\mathrm{P}}=40-d_{\mathrm{P}}$ ). According to the relevant standard, the time when the $d_{\mathrm{P}}$ reaches value of $6 \pm 3 \mathrm{~mm}$, measured to the nearest minute, was determined from the obtained $d_{\mathrm{p}}-t$ curve and defined as the initial setting time $t_{\mathrm{I}}$ of the material. The time of the last measurable $d_{\mathrm{P}}$ value, representing the final value of the $d_{\mathrm{P}}-t$ curves (i.e. the value of $d_{\mathrm{P}}$ close to $40 \mathrm{~mm}$ ) was chosen as the final setting time $t_{\mathrm{F}}$ in this study. After that (at the next consecutive test time), the penetration into the material was not possible any more.

\subsubsection{Statistical methods}

Basic descriptive statistics were used to quantitatively describe main features of a collection of experimental data, namely maximum, minimum, and median values. To measure dispersion that accompanies the median, an interquartile range (IQR) was used, being the range of values within which reside the middle $50 \%$ of the scores (i.e. the distance between the upper $\mathrm{Q}_{3}$ and lower $\mathrm{Q}_{1}$ quartiles).

\subsection{Experimental materials}

\subsubsection{Cements}

The cements used in the investigation were Type I and Type II Portland cements with the characteristics presented in Table 1. AC and BS in the table stand for the clinker content and Blaine surface of the cement, respectively. The calculated Bogue compositions of the cements (mass fractions) were deduced from a chemical characterization.

Table 1. Basic characteristics of the cements used in the study.

\begin{tabular}{lllllll}
\hline cement type & $\mathrm{AC}[\%]$ & $\mathrm{BS}\left[\mathrm{cm}^{2} / \mathrm{g}\right]$ & $\mathrm{C}_{3} \mathrm{~S}[\%]$ & $\mathrm{C}_{2} \mathrm{~S}[\%]$ & $\mathrm{C}_{3} \mathrm{~A}[\%]$ & $\mathrm{C}_{4} \mathrm{AF}[\%]$ \\
\hline CEM II/A-S 42,5R & $>80$ & 4260 & 32.85 & 46.32 & 10.36 & 10.47 \\
CEM I 52,5 R & $>95$ & 4310 & 57.70 & 13.00 & 6.90 & 8.90 \\
CEM I 42,5 N & $>95$ & 2640 & 60.20 & 13.60 & 7.20 & 9.30 \\
CEM I 42,5 N SR & $>95$ & 3130 & 55.90 & 21.90 & 2.30 & 15.00 \\
\hline
\end{tabular}

\subsubsection{Cement pastes}

Twenty different cement pastes were prepared to reach a wide range of hydration kinetics on which to test the proposed methodology. The pastes are summarized in Table 2 and can be divided into five groups, depending on the cement paste composition and curing temperature. Labeling of the pastes is according to a dominant variable of each group.

To get three different values of cement fineness, cement types CEM I 52,5R and CEM I 42,5N were used separately and one mixture (BS $=3490 \mathrm{~cm}^{2} / \mathrm{g}$ ) was prepared by combining these two cements in equal amounts. This was possible due to very similar chemical composition of these cements. Similar procedure was used to obtain three values of $\mathrm{C}_{3} \mathrm{~A}$ where cement types CEM I 42,5N SR and CEM I 42,5N were used. 
Table 2. Cement paste mixtures used in the study.

\begin{tabular}{|c|c|c|c|c|c|}
\hline $\begin{array}{c}\text { Mixture } \\
\text { label }\end{array}$ & $\begin{array}{c}\text { Cement } \\
\text { type }\end{array}$ & w/c & $\begin{array}{c}S P \\
{\left[\mathrm{~cm}^{2} / \mathrm{g}\right]}\end{array}$ & $\begin{array}{l}\mathrm{C}_{3} \mathrm{~A} \\
{[\%]}\end{array}$ & $\begin{array}{c}\boldsymbol{T}_{\mathrm{A}} \\
{\left[{ }^{\circ} \mathrm{C}\right]}\end{array}$ \\
\hline $\mathrm{w} / \mathrm{c}=0.30$ & CEM II/A-S 42,5R & 0.30 & 4260 & 10.4 & 20 \\
\hline $\mathrm{w} / \mathrm{c}=0.35$ & CEM II/A-S 42,5R & 0.35 & 4260 & 10.4 & 20 \\
\hline $\mathrm{w} / \mathrm{c}=0.40$ & CEM II/A-S 42,5R & 0.40 & 4260 & 10.4 & 20 \\
\hline \multirow{4}{*}{$\mathrm{w} / \mathrm{c}=0.50$} & CEM II/A-S 42,5R & 0.50 & 4260 & 10.4 & 11 \\
\hline & CEM II/A-S 42,5R & 0.50 & 4260 & 10.4 & 21 \\
\hline & CEM II/A-S 42,5R & 0.50 & 4260 & 10.4 & 26 \\
\hline & CEM II/A-S 42,5R & 0.50 & 4260 & 10.4 & 32 \\
\hline \multirow{4}{*}{$\mathrm{w} / \mathrm{c}=0.60$} & CEM II/A-S 42,5R & 0.60 & 4260 & 10.4 & 11 \\
\hline & CEM II/A-S 42,5R & 0.60 & 4260 & 10.4 & 20 \\
\hline & CEM II/A-S 42,5R & 0.60 & 4260 & 10.4 & 26 \\
\hline & CEM II/A-S 42,5R & 0.60 & 4260 & 10.4 & 32 \\
\hline $\mathrm{w} / \mathrm{c}=0.65$ & CEM II/A-S 42,5R & 0.60 & 4260 & 10.4 & 20 \\
\hline CEM I 42,5 N & \multirow[b]{2}{*}{ CEM I 42,5 N } & \multirow[b]{2}{*}{0.50} & \multirow[b]{2}{*}{2640} & \multirow[b]{2}{*}{7.2} & \multirow[b]{2}{*}{20} \\
\hline $\begin{array}{l}S P=2640 \mathrm{~cm}^{2} / \mathrm{g} \\
\mathrm{C}_{3} \mathrm{~A}=7.2 \%\end{array}$ & & & & & \\
\hline $\begin{array}{l}\text { CEM I 42,5 N SR } \\
\mathrm{C}_{3} \mathrm{~A}=2.3 \%\end{array}$ & CEM I 42,5 N SR & 0.50 & 3130 & 2.3 & 20 \\
\hline $\begin{array}{l}\text { CEM I 52,5 R } \\
S P=4310 \mathrm{~cm}^{2} / \mathrm{g}\end{array}$ & CEM I 52,5 R & 0.50 & 4310 & 2.6 & 20 \\
\hline CEM I 42,5 N & CEM I 42,5 N & 0.40 & 2640 & 7.2 & 20 \\
\hline CEM I 42,5 N SR & CEM I 42,5 N SR & 0.40 & 3130 & 2.3 & 20 \\
\hline CEM I 52,5 R & CEM I 52,5 R & 0.40 & 4310 & 2.6 & 20 \\
\hline$S P=3490 \mathrm{~cm}^{2} / \mathrm{g}$ & $\begin{array}{l}\text { CEM I 52,5 R } \\
\text { CEM I 42,5 N }\end{array}$ & 0.50 & 3490 & 7.1 & 20 \\
\hline $\mathrm{C}_{3} \mathrm{~A}=4.8 \%$ & $\begin{array}{c}\text { CEM I 42,5 N } \\
\text { CEM I 42,5 N SR }\end{array}$ & 0.50 & 2800 & 4.8 & 20 \\
\hline
\end{tabular}

\subsubsection{Sample preparation and experimental procedure}

About $80 \mathrm{~cm}^{3}$ of each cement paste was mixed according to European EN 196-1 standard. For all cement pastes, the duration of mixing was $2 \mathrm{~min}$ from the initial contact of cement with water. Afterward, about 2 $\mathrm{cm}^{3}$ of the material was smeared into the mould and all the samples were sealed with thermoplastic laboratory film to prevent water evaporation.

Within the present study, $\Delta r$ measurements started immediately after casting (i.e. 2 min after first contact of cement with water) and were carried out continuously over duration of approximately 40 hours after mixing. US measurements were conducted in a climate chamber at $T_{\mathrm{A}} \pm 1{ }^{\circ} \mathrm{C}$ and $60 \%$ relative humidity. 
The results were recorded at 1 min time intervals, resulting in a $\Delta r-t$ diagram for each cement paste mixture.

\section{RESULTS AND DISCUSSION}

\subsection{Typical development of the $\Delta r$ coefficient in time}

Fig. 2 shows typical evolution of the change of the shear wave reflection coefficient $\Delta r$ and the rate (numerical time derivative $\mathrm{d} \Delta r / \mathrm{d} t$ ) of $\Delta r$, labeled as $\Delta r^{\prime}$, for a typical cement paste mixture during the first 24 hours. As an example, a typical shape of the waveform in time domain showing multiple reflections in the case of cement paste is presented in Fig. 3. The presented waveform belongs to the cement paste presented in Fig. 2 and was obtained at the time $t=5.2 \mathrm{~h}$.

a)

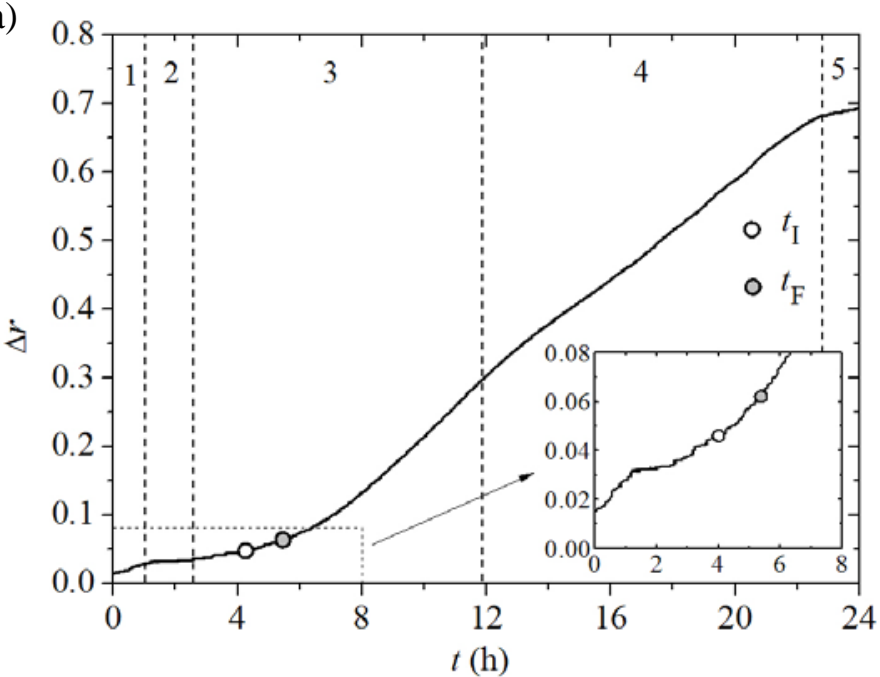

b)

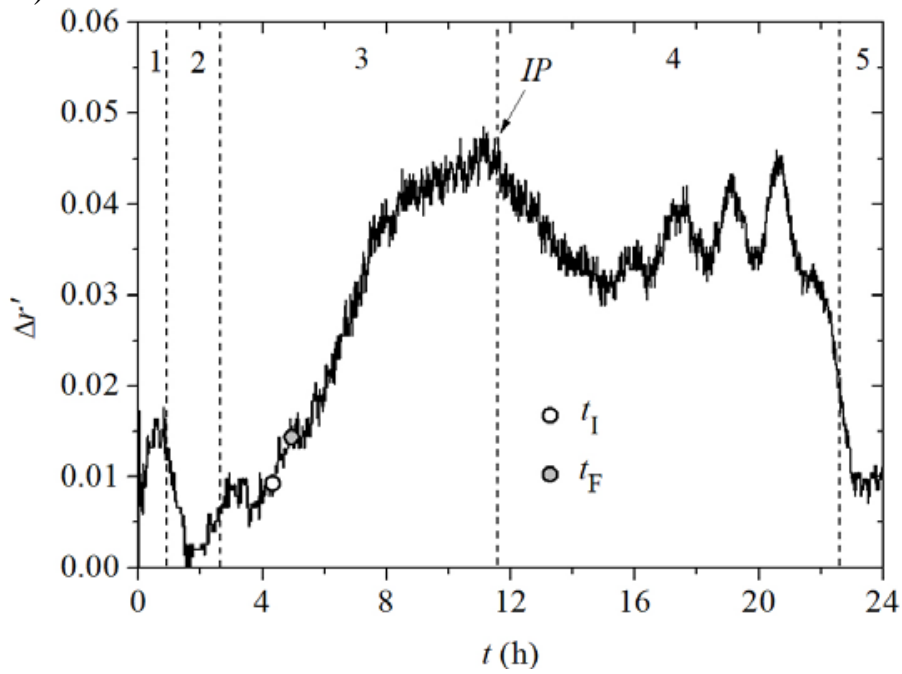

Fig. 2. Typical evolution of the $\Delta r$ and rate of $\Delta r$ coefficient in time; a) $\Delta r-t$ curve, b) $\Delta r^{\prime}-t$ curve.

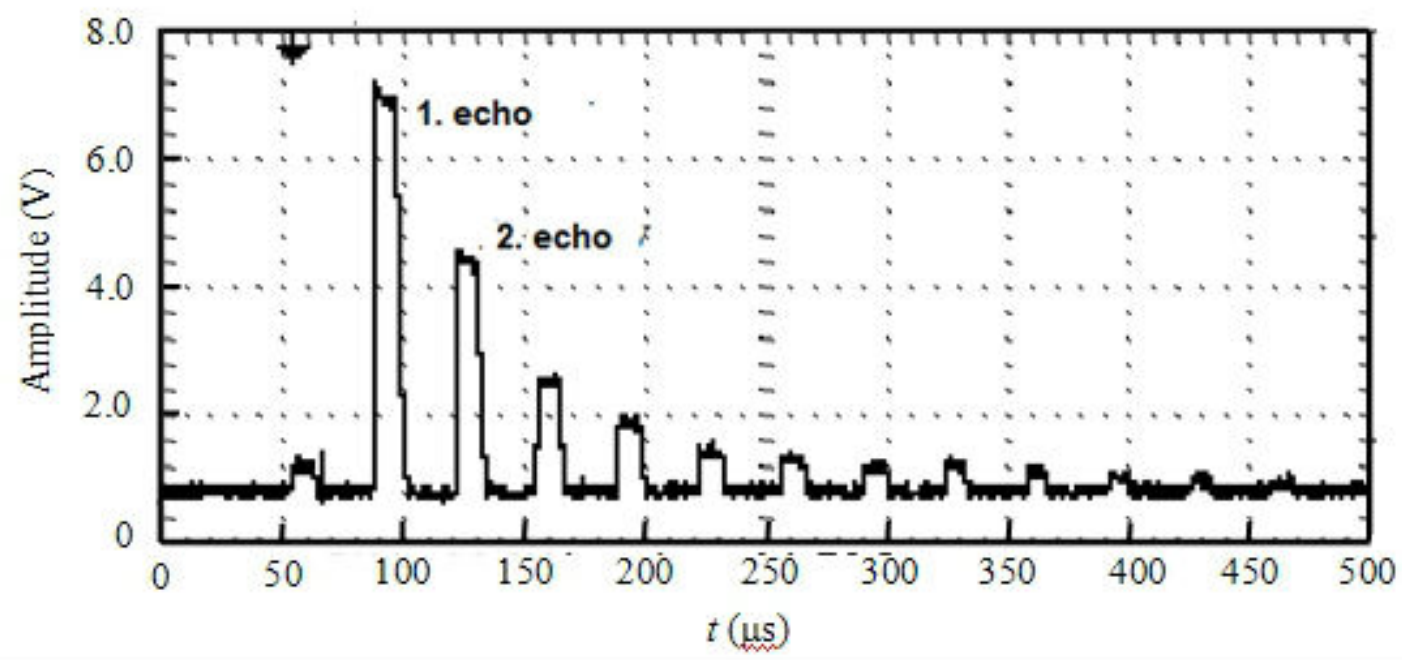

Fig. 3. Typical waveform of multiple reflections in time domain.

According to Sun et al. [14,16] a typical curve of the development of reflection loss in time can be divided into three stages. Using the presented USWR method, five stages can be defined on the basis of the $\Delta r$ and $\Delta r^{\prime}$ evolution in time (see Fig. 2). The partition of the hydration process into five stages corresponds well with the observations presented by some other researchers (e.g. [25]) who based their 
research on the heat release during the hydration process. Stage 1 occurs immediately after water is first added to the cement. During this stage a short period of a small increase of $\Delta r$ value is observed which, depending of the cement paste composition, usually lasts for about $15-30$ minutes. During the $2^{\text {nd }}$ stage (dormant stage), the rate of the initial reaction is slowed down and a short plateau is reached on the $\Delta r-t$ diagram, indicating a considerable plasticity of the material. During stage 3 (acceleration stage), $\Delta r$ values start to increase slowly at first and faster later up to the inflection point $I P$, presented on the $\Delta r^{\prime}-t$ curve (Fig. 2b). This characteristic point represents maximum rate of $\Delta r$ evolution in time and separates stages 3 and 4 . The intensive increase in $\Delta r$ during the $3^{\text {rd }}$ stage could be attributed to an intensive growth of different hydration products [21] and consequently increasing amount of the total and the connected solid phase in the microstructure of the material [26]. During the $4^{\text {th }}$ stage (deceleration stage) the rate of $\Delta r$ increase slows down (see Fig. 2b) until a final period on the $\Delta r-t$ curve is reached. At this moment stage 5 begins, representing a continuing slow increase of the $\Delta r$ values.

In Fig. 2, hollow and solid circles represent initial and final setting times, respectively, and were obtained by marking points on the $\Delta r-t$ and $\Delta r^{\prime}-t$ curves, corresponding to the initial $\left(t_{\mathrm{I}}\right)$ and final $\left(t_{\mathrm{F}}\right)$ setting times, determined using standard Vicat method. As can be seen from inset graph in Fig. 2a, these characteristic points appear during the period of unambiguous increase in $\Delta r$ values and therefore indicate possibility of using $\Delta r$ values to estimate initial and final setting times. Relationship between setting times and $\Delta r$ values will be discussed in detail for all analyzed mixtures later in the article.

Unaffected steep increase in $\Delta r$ values far beyond the final setting time when penetration into the material is not possible any more is also evident from Fig. 2, indicating ability of the proposed US method to detect microstructural changes that occur after the setting period of the material. As will be demonstrated later in the article, this is an important advantage over penetration resistance methods which enables observation of some interesting phenomena that occur after the setting period.

\subsection{Influence of cement paste composition on the development of $\Delta r$ coefficient in time}

A possibility and repeatability of using the USWR method to study the influence of the cement paste composition and curing temperatures on the hydration process and formation of the material microstructure has been already briefly indicated by the authors in [27]. However, to reach the focus of this research, many additional cement paste mixtures were analyzed. As a result, development of $\Delta r-t$ curves for all analyzed cement paste mixtures is presented in Fig. 4.

First, a wide range of w/c ratio was analyzed with the results presented in Fig. 4a. As expected, mixtures with higher w/c ratio show lower $\Delta r$ values which can be related to the microstructure of the cement paste. The evolution of the US pulse velocity was found to be correlated to the amount of a total and connected solid phase [26] and it is well known that these two quantities are higher in the case of lower w/c ratio.

In Fig. 4b, the influence of the cement type on the development of the $\Delta r$ values in time is presented. This analysis was performed on cement paste mixtures with two different w/c ratios. Light and dark curves represent mixtures with w/c ratio of 0.50 and 0.40 , respectively. It is evident that cement type has a significant influence on the evolution of the $\Delta r$ values. Interestingly, higher differences between different cement types were observed in the case of lower w/c ratio.

The influence of cement fineness is shown in Fig 4c. It can be seen that cement fineness has an important influence on the evolution of $\Delta r$ values and as expected, higher fineness results in a more rapid hydration process and consecutively to a more rapid evolution of the $\Delta r$.

Fig. $4 \mathrm{~d}$ demonstrates the influence of the amount of tri-calcium aluminate $\left(\mathrm{C}_{3} \mathrm{~A}\right)$ on the evolution of the $\Delta r-t$ curves. Lower amount of $\mathrm{C}_{3} \mathrm{~A}$ results in slower evolution of the $\Delta r$ values. 
a)

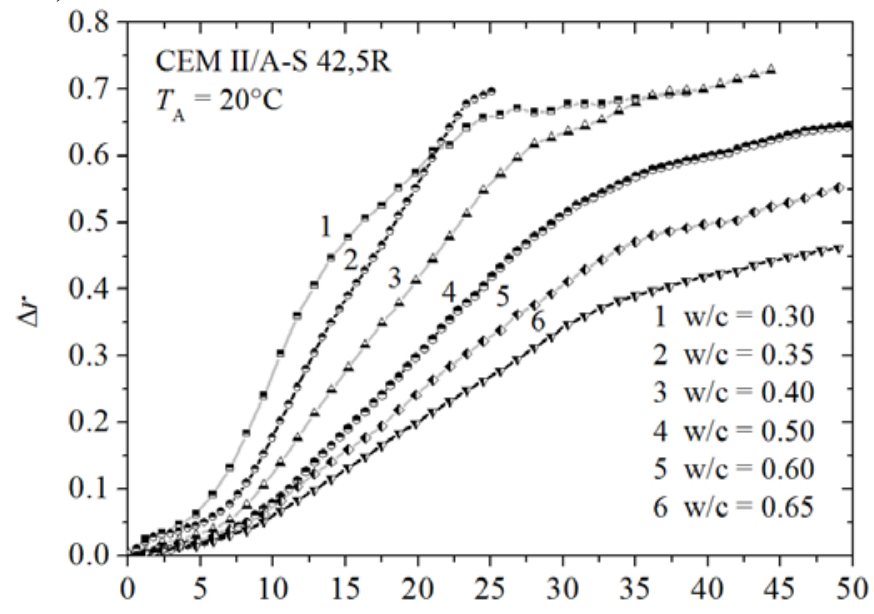

c)

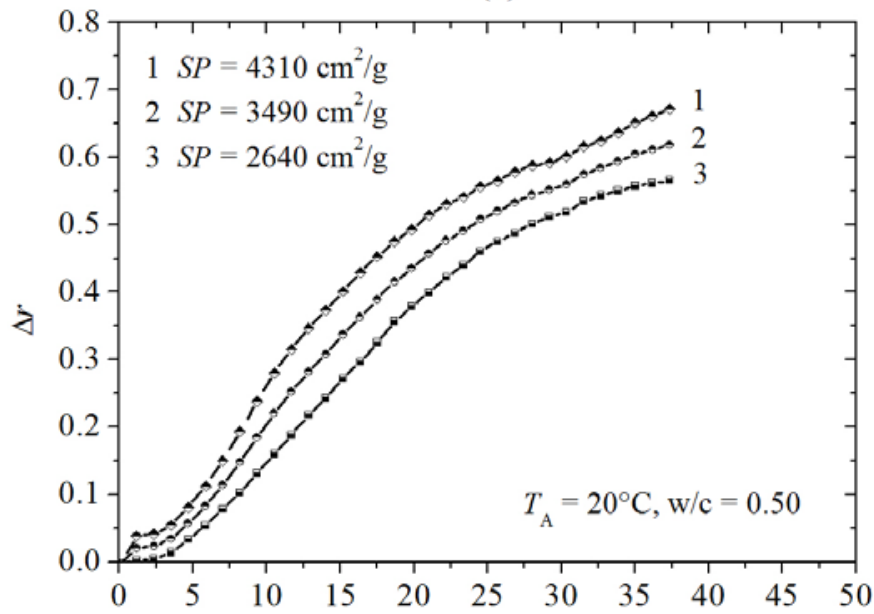

e)

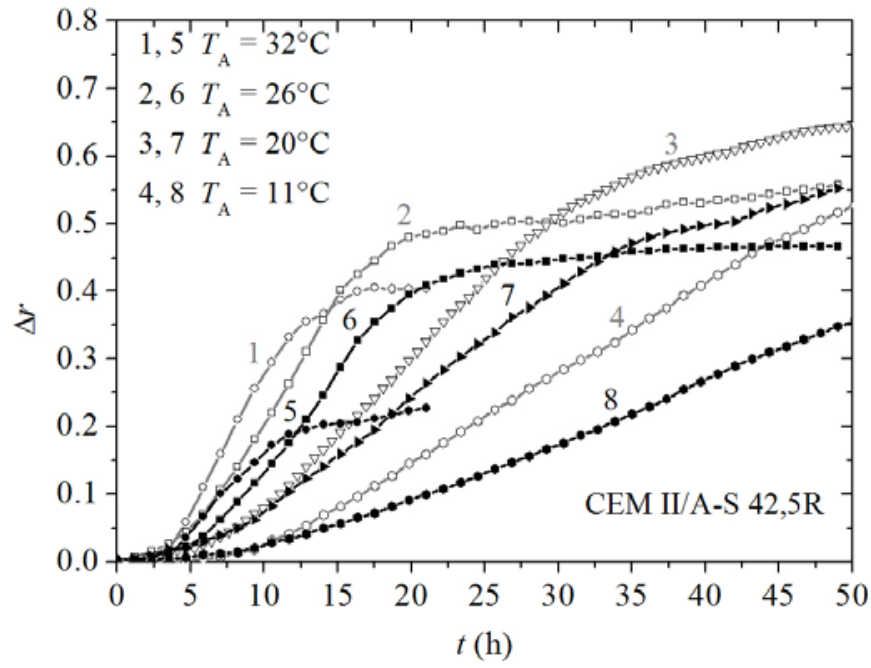

b)

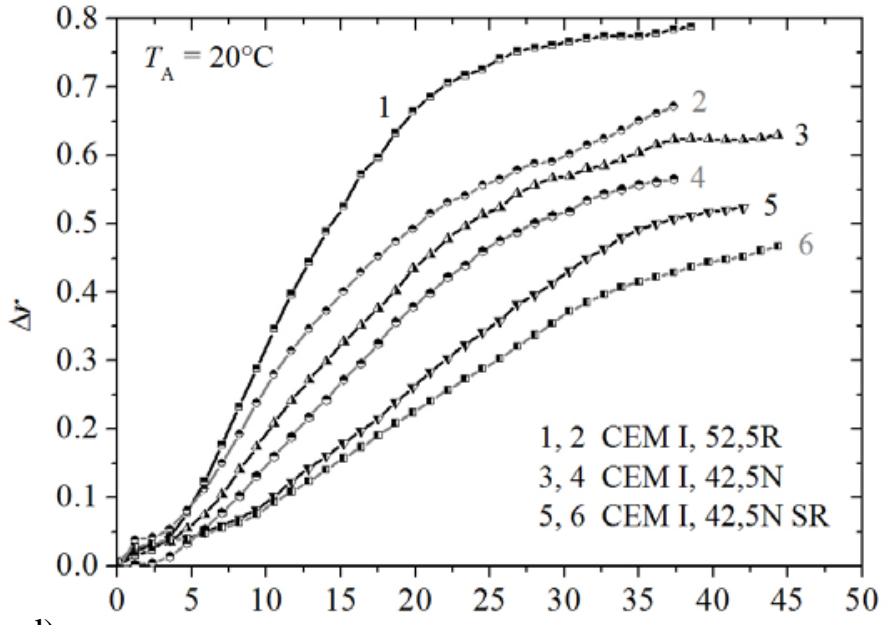

d)

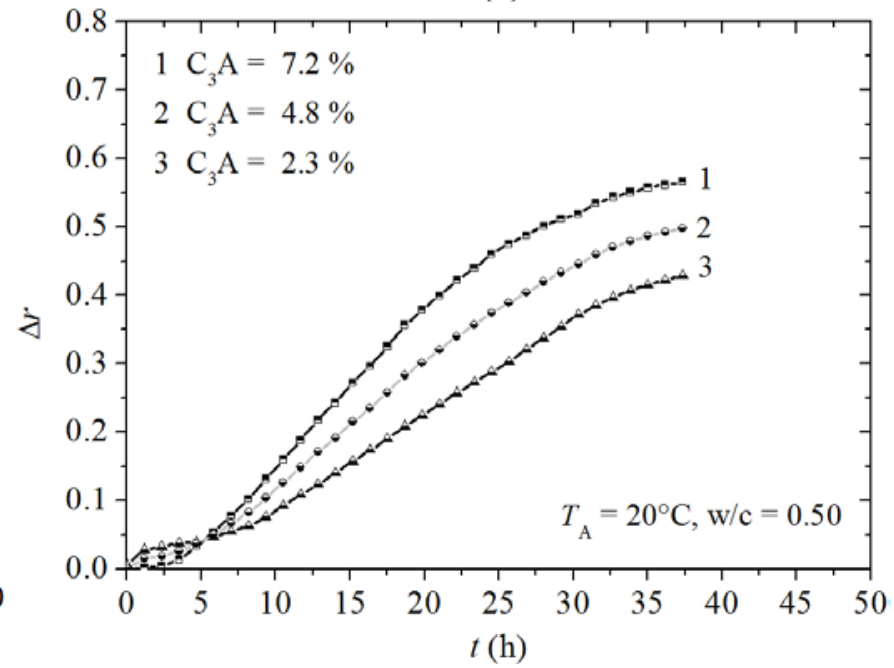

Fig. 4. The development of the $\Delta r$ coefficient in time influenced by; a) w/c ratio, b) cement type, c) cement fineness, d) $\mathrm{C}_{3} \mathrm{~A}$ amount, e) curing temperature.

In Fig. 4e, the influence of curing temperature on the development of the $\Delta r-t$ curves is presented. Again, this analysis was performed on cement paste mixtures with two different w/c ratios. Light and dark curves represent the mixtures with the w/c ratio of 0.50 and 0.60 , respectively. It is seen that higher curing temperatures result in a more rapid increase of the $\Delta r$ values at the very beginning of the hydration process. However, as the hydration progresses, the $\Delta r-t$ curves intersect at a certain hydration time, resulting into higher long-term $\Delta r$ values in the case of lower curing temperature. As can be seen from 
Fig. 4e, the time of the intersection decreases with increasing curing temperature and decreasing w/c ratio. This interesting phenomenon can be attributed to a well known cross-over effect [28] which has been already observed by many researchers in the case when the influence of the curing temperature on the development of concrete compressive strength [29-31] and the influence of an initial concrete temperature on the development of adiabatic hydration curves [32] was analyzed. The cross-over effect can be explained by the fact that the increased rate of the hydration caused by higher curing temperatures does not allow sufficient time for proper distribution of various hydration products and a barrier forms around cement particles and hydration products, resulting into a weaker bond between the hydration products which hinders further hydration and formation of structure of cement based materials [17, 31, 33]. Although similar cross-over effect has been briefly presented by Sun [16], it was less evident in this case.

It is also seen that in some diagrams of Fig. 4 a very small increase in $\Delta r$ values occurs at time $t=0$, i.e. immediately after contact of the probe with the test sample. It is believed that this is due to viscoelastic nature of cement pastes at the very early hydration period in which shear modules is a complex quantity with a very small real component [12], value of which depends on the cement paste composition. This interesting phenomenon is even more observed in Figs. 5, which show the development of the $\Delta r-t$ curves during the early hydration process (up to $12 \mathrm{~h}$ ). The initial increase is more pronounced in the case of lower w/c ratio (see Fig. 5a and 5b) and higher cement fineness (Fig. 5g) and is attributed to a denser material in these cases. Since the effect depends on the cement paste composition, the initial increase in $\Delta r$ is not influenced by different curing temperature which can be clearly seen from Figs. 5c and $5 \mathrm{~d}$. Interestingly, higher initial increase in $\Delta r$ values was observed in the case of lower $\mathrm{C}_{3} \mathrm{~A}$ content (see Fig. 5h). Using similar USWR technique, such, but much larger changes were measured and documented in the case of visco-elastic (non-cementitious) materials, like bitumen, epoxy, and motor oils [34].

Significant differences in the evolution of the $\Delta r-t$ curves indicate that USWR method could represent an advanced NDT technique to monitor the setting and hardening process of cement based materials from the very beginning of the hydration process.

\subsection{Comparison between $\Delta r$ and $d_{\mathrm{P}}$ development in time}

In Fig. 5, comparisons between $\Delta r$ (solid curves, right $y$ axis) and $d_{\mathrm{P}}$ (dashed curves, left $y$ axis) development in time are presented for all analyzed cement paste mixtures. For clarity, time axes are reduced to the period from $0-12$ hour. In the figure, initial and final setting times are presented on each $\Delta r-t$ curve as hollow and solid dots, respectively, which were obtained by marking points on $\Delta r-t$ curves corresponding to the setting times, determined from dashed $d_{\mathrm{P}}-t$ curves using standard Vicat method. Dotted horizontal lines in the figures represent value of $d_{\mathrm{P}}=6 \mathrm{~mm}$, which is used as a criterion to define initial setting time (refer to section 2.1.2). In the case of the lowest curing temperature (i.e. $T_{\mathrm{A}}=$ $11^{\circ} \mathrm{C}$ in this study), the final setting times are not indicated in the figures since they appear after the first 12 hours (refer to Table 3). As expected, initial and final setting times are influenced by cement type significantly and decrease with decreasing w/c ratio and increasing curing temperature, cement fineness, and $\mathrm{C}_{3} \mathrm{~A}$ amount.

Fig. 5 indicates that the two characteristic points appear after the dormant stage on the corresponding $\Delta r$ - $t$ curve. Next, it can be seen from this figure and Table 3 that $\Delta r_{\mathrm{I}}$ values, corresponding to the initial setting time $t_{\mathrm{I}}$, do not appear at the same $\Delta r$ level. This is an important observation and is in contrast to the results presented by Sun et al. [14], who performed a similar study on three cement pastes with different w/c ratios (0.35-0.60) and indicated that all three pastes had a very similar value of the reflection loss. The largest differences between $\Delta r_{\mathrm{I}}$ values were observed for different curing temperatures (Figs. 5c and 5d) and decrease with the decreasing curing temperatures.

According to the results presented in Table 3 , average $\Delta r_{\mathrm{I}}$ value is $0.052(0.050,0.055)$ with a standard deviation of 0.017 where values in brackets stand for $95 \%$ confidence interval. Differences between $\Delta r_{\mathrm{I}}$ values can be attributed to different mechanisms of the USWR and penetration resistance methods and initial increase in $\Delta r$ values in the case of some cement pastes (refer to section 3.2). 
a)

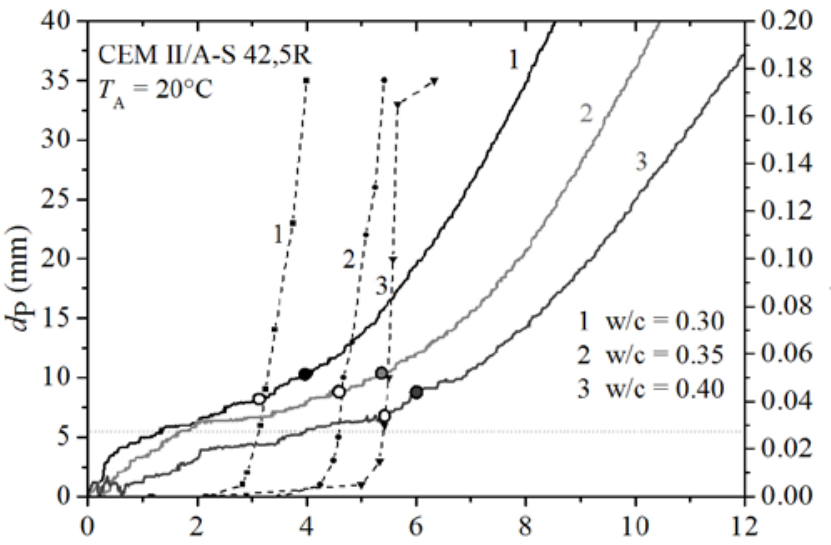

c)

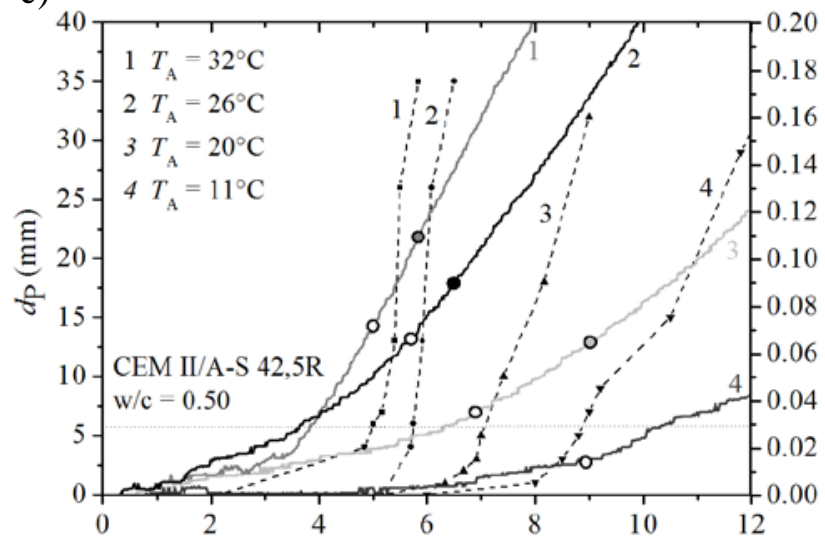

e)

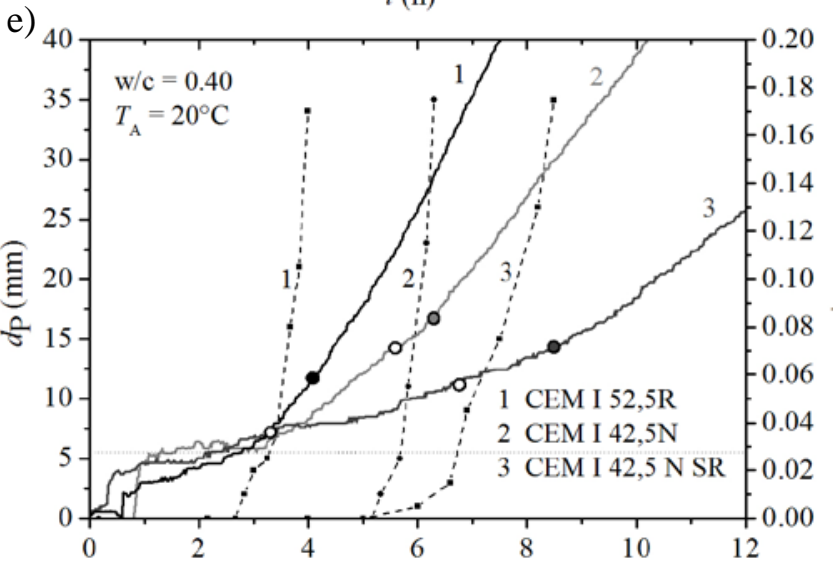

g)

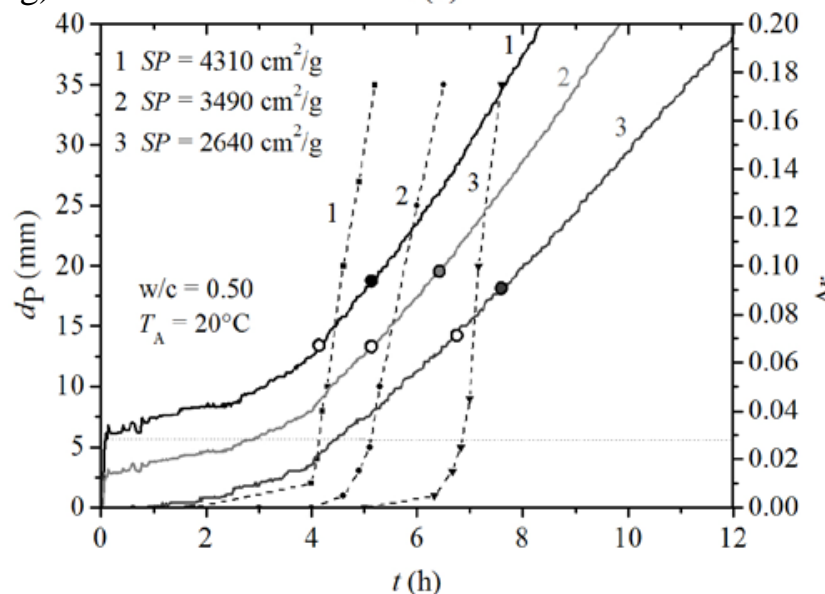

b)

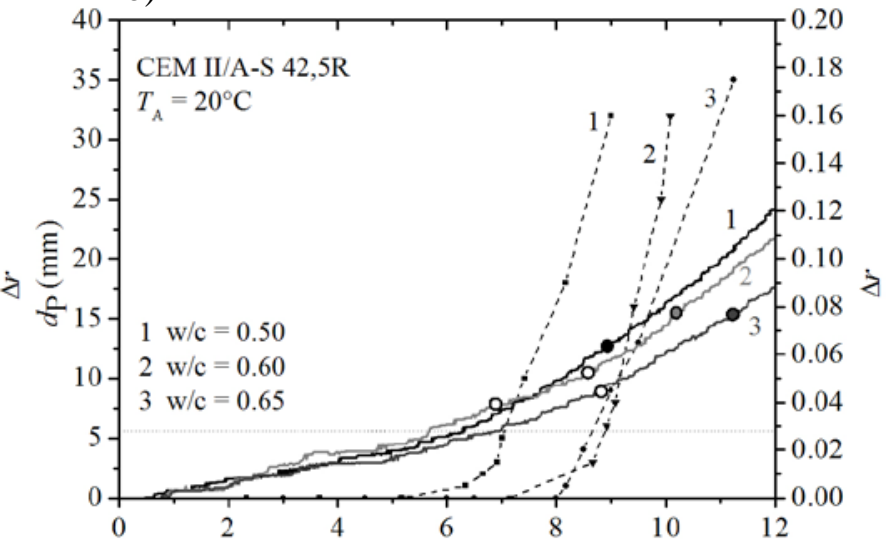

d)

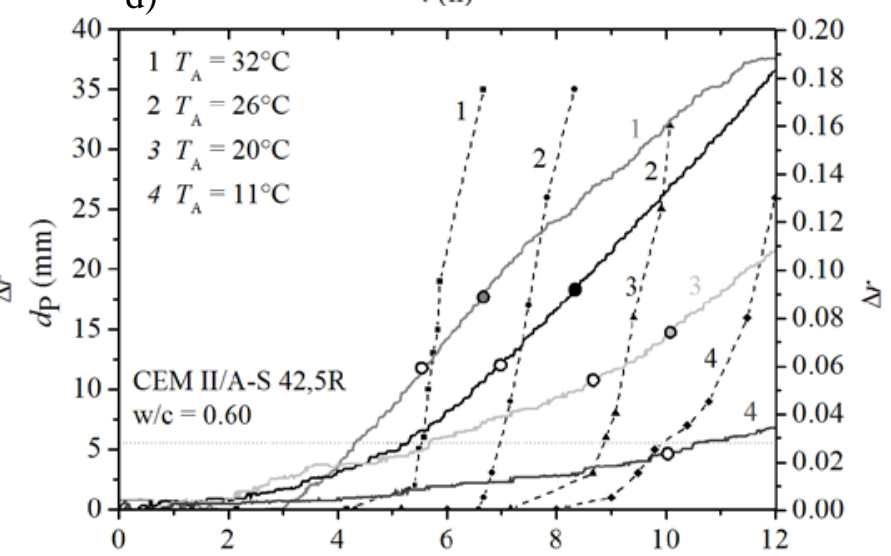

$t$ (h)

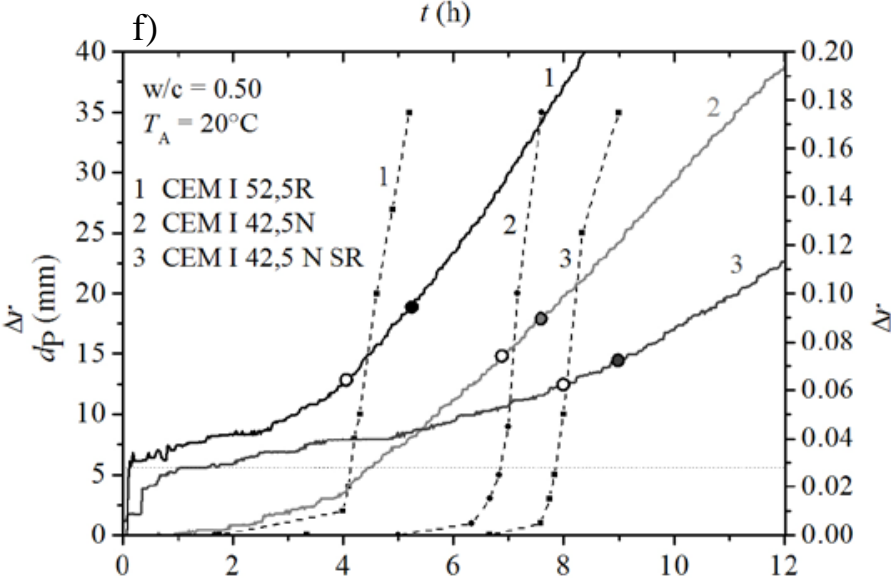

h)

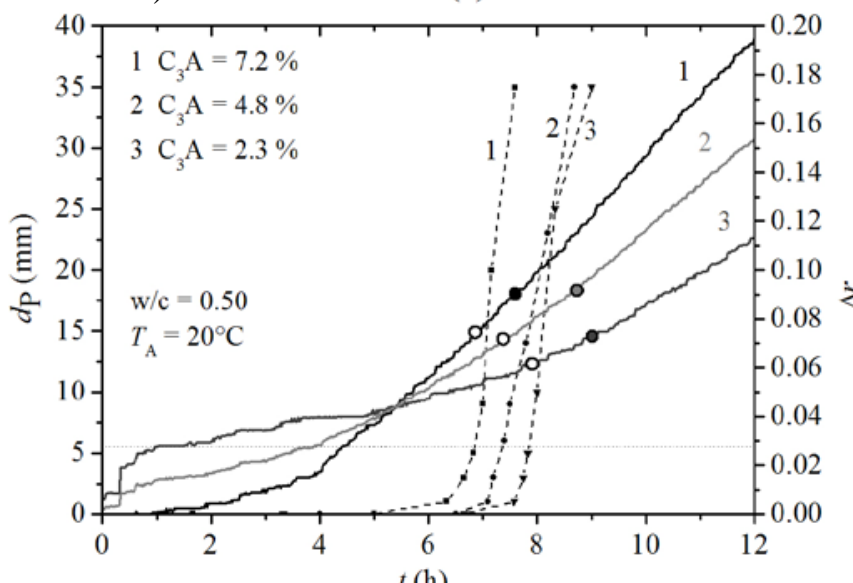

$t$ (h)

Fig. 5. Relationship between $\Delta r$ and $d_{\mathrm{P}}$ development in time, influenced by; a,b) w/c ratio; c,d) curing temperature; e,f) cement type; g) cement fineness; h) $\mathrm{C}_{3} \mathrm{~A}$ amount. 
Table 3. Setting times and correlation coefficients of $\Delta r-d_{\mathrm{P}}$ relationship for all cement paste mixtures analyzed in the study.

\begin{tabular}{|c|c|c|c|c|c|c|c|}
\hline \multirow{2}{*}{\multicolumn{2}{|c|}{$\begin{array}{l}\text { mixture } \\
\text { label }\end{array}$}} & \multicolumn{4}{|c|}{ setting times } & \multicolumn{2}{|c|}{$\Delta r-d_{\mathrm{P}}$ relationship } \\
\hline & & $t_{\mathrm{I}}(\mathrm{h})$ & $\Delta r_{\mathrm{I}}(-)$ & $t_{\mathrm{F}}(\mathrm{h})$ & $\Delta r_{\mathrm{F}}(-)$ & $\mathrm{R}_{\log }^{2}$ & $\mathrm{R}_{\text {lin }}^{2}$ \\
\hline \multirow{6}{*}{ 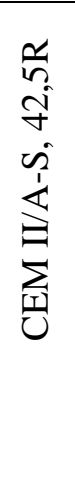 } & $\mathrm{w} / \mathrm{c}=0.30$ & 3.1 & 0.041 & 4.0 & 0.051 & 0.98 & 0.98 \\
\hline & $\mathrm{w} / \mathrm{c}=0.35$ & 4.3 & 0.043 & 5.4 & 0.051 & 0.93 & 0.94 \\
\hline & $\mathrm{w} / \mathrm{c}=0.40$ & 5.3 & 0.033 & 6.1 & 0.043 & 0.81 & 0.75 \\
\hline & $\begin{array}{l}\mathrm{w} / \mathrm{C}=0.50, \\
T_{\mathrm{A}}=20^{\circ} \mathrm{C}\end{array}$ & 6.8 & 0.040 & 9.0 & 0.061 & 0.93 & 0.84 \\
\hline & $\begin{array}{l}\mathrm{w} / \mathrm{c}=0.60, \\
T_{\mathrm{A}}=20^{\circ} \mathrm{C}\end{array}$ & 8.7 & 0.051 & 10.1 & 0.078 & 0.90 & 0.95 \\
\hline & $\mathrm{w} / \mathrm{c}=0.65$ & 8.9 & 0.042 & 11.2 & 0.078 & 0.96 & 0.98 \\
\hline \multirow{3}{*}{$\begin{array}{l}q \\
0 \\
11 \\
0 \\
3\end{array}$} & CEM I 52,5R & 3.2 & 0.038 & 4.0 & 0.058 & 0.95 & 0.98 \\
\hline & CEM I 42,5N & 5.5 & 0.072 & 6.2 & 0.082 & 0.97 & 0.85 \\
\hline & CEM I 42,5N SR & 6.8 & 0.057 & 8.3 & 0.071 & 0.93 & 0.85 \\
\hline \multirow{3}{*}{$\begin{array}{l}\text { 웅 } \\
0 \\
11 \\
\frac{0}{3}\end{array}$} & $\begin{array}{l}\text { CEM I 52,5R } \\
S P=4310 \mathrm{~cm}^{2} / \mathrm{g}\end{array}$ & 4.1 & 0.062 & 5.2 & 0.093 & 0.95 & 0.97 \\
\hline & $\begin{array}{l}\text { CEM I } 42,5 \mathrm{~N} \\
S P=2640 \mathrm{~cm}^{2} / \mathrm{g} \\
\mathrm{C}_{3} \mathrm{~A}=7.2 \%\end{array}$ & 6.8 & 0.074 & 7.7 & 0.091 & 0.92 & 0.83 \\
\hline & $\begin{array}{l}\text { CEM I 42,5N SR } \\
\mathrm{C}_{3} \mathrm{~A}=2.3 \%\end{array}$ & 7.9 & 0.061 & 9.1 & 0.071 & 0.98 & 0.97 \\
\hline \multirow{3}{*}{$\begin{array}{l}0 \\
\text { ำ } \\
0 \\
11 \\
u \\
3\end{array}$} & $T_{\mathrm{A}}=32^{\circ} \mathrm{C}$ & 5.0 & 0.071 & 5.9 & 0.110 & 0.87 & 0.89 \\
\hline & $T A=26^{\circ} \mathrm{C}$ & 5.8 & 0.066 & 6.4 & 0.090 & 0.94 & 0.97 \\
\hline & $T_{\mathrm{A}}=11^{\circ} \mathrm{C}$ & 9.0 & 0.013 & 13.1 & 0.048 & 0.96 & 0.97 \\
\hline \multirow{3}{*}{$\begin{array}{l}0 \\
0 \\
0 \\
11 \\
u \\
3\end{array}$} & $T_{\mathrm{A}}=32^{\circ} \mathrm{C}$ & 5.6 & 0.060 & 6.7 & 0.090 & 0.96 & 0.98 \\
\hline & $T_{\mathrm{A}}=26^{\circ} \mathrm{C}$ & 7.0 & 0.059 & 8.3 & 0.092 & 0.99 & 0.99 \\
\hline & $T_{\mathrm{A}}=11^{\circ} \mathrm{C}$ & 10.2 & 0.024 & 13.3 & 0.047 & 0.96 & 0.87 \\
\hline- & $S P=3490 \mathrm{~cm}^{2} / \mathrm{g}$ & 5.1 & 0.068 & 6.5 & 0.098 & 0.98 & 0.98 \\
\hline- & $\mathrm{C}_{3} \mathrm{~A}=4.8 \%$ & 7.3 & 0.071 & 8.9 & 0.092 & 1.00 & 1.00 \\
\hline
\end{tabular}

Similarly, $\Delta r_{\mathrm{F}}$ values, corresponding to the final setting times $t_{\mathrm{F}}$, do not appear at the same $\Delta r$ level, which is in agreement with the results presented by Sun et al. [14,16] and further substantiates the assumption that shear wave reflection coefficient and penetration resistance should be related to the presence of some different phenomena that appear during the stiffening process of cement pastes. Average $\Delta r_{\mathrm{F}}$ value was determined to be $0.074(0.071,0.077)$ in this study. Again, the largest differences were observed in the case of different curing temperatures (Figs. 5c and 5d).

In Fig. 6, relationships between $\Delta r$ and $d_{\mathrm{P}}$ values are presented for the whole setting period until the cement pastes were completely set. The $\Delta r-d_{\mathrm{P}}$ diagrams were obtained from Fig. 5 by plotting $\Delta r$ vs. $d_{\mathrm{P}}$ values at equal times $t$. A dashed line indicates the initial setting (i.e. $d_{\mathrm{P}}=6 \mathrm{~mm}$ ). Concerning the results presented in Fig. 6, both linear and logarithmic relationships between the change of the shear wave reflection coefficient and penetration resistance were studied. In Table 3, correlation coefficients $\mathrm{R}_{\text {lin }}^{2}$ and 
$\mathrm{R}_{\text {log }}^{2}$, representing correlation coefficients in the case of linear and logarithmic $\Delta r-d_{\mathrm{P}}$ relationships, respectively, are summarized for all analyzed cement paste mixtures. Average correlation coefficients in the case of linear and logarithmic relationships were determined to be $0.93(0.92,0.94)$ and $0.94(0.94$, 0.95), respectively, where values in brackets stand for the $95 \%$ confidence intervals. High $\mathrm{R}^{2}{ }_{\operatorname{lin}}$ and $\mathrm{R}_{\log }^{2}$ values indicate that the shear wave reflection coefficient clearly reflects evolution of the (connected) solid phase in cement paste during the whole setting period. However, the $\Delta r-d_{\mathrm{P}}$ relationship is not unique, proving different sensitivity of both methods to the presence of various parameters which influence the hydration kinetics.

a)

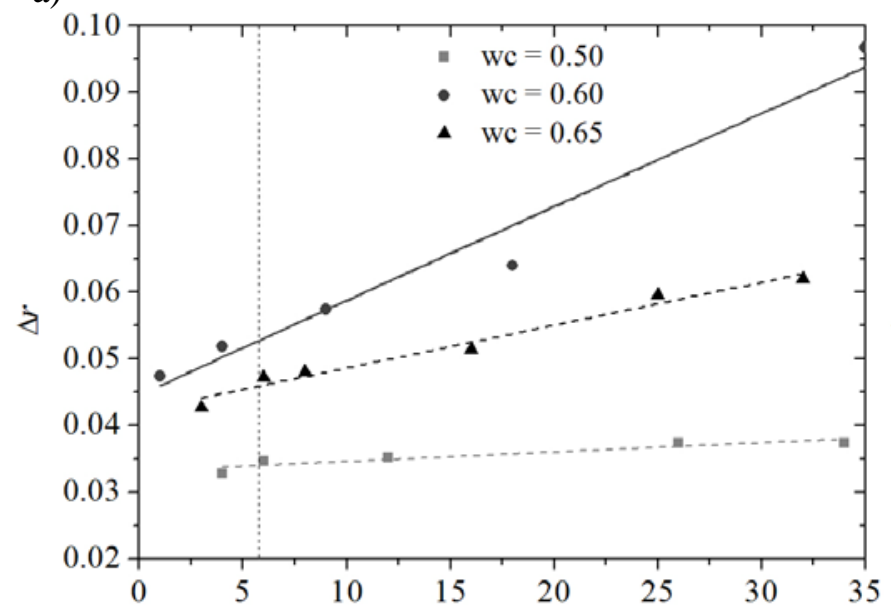

c)

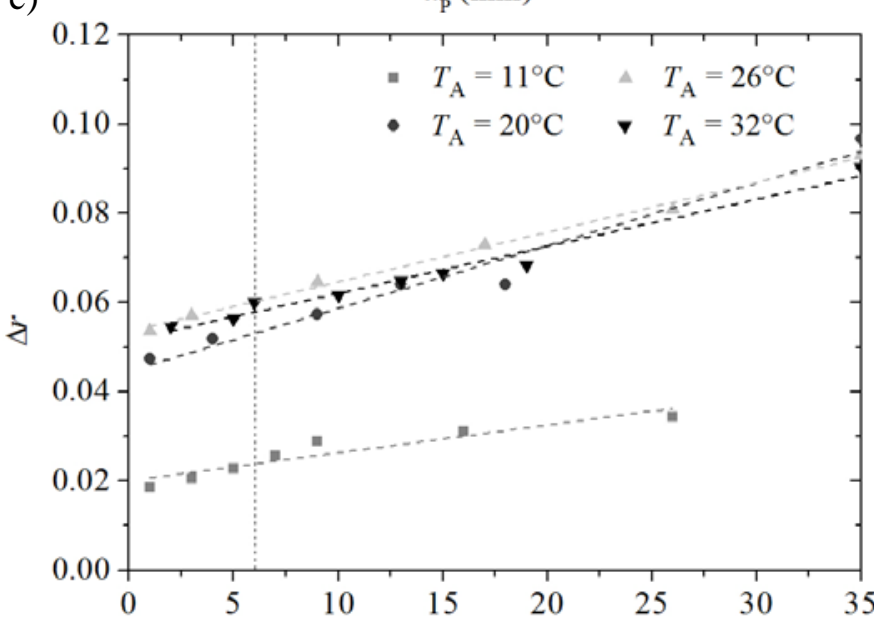

e)

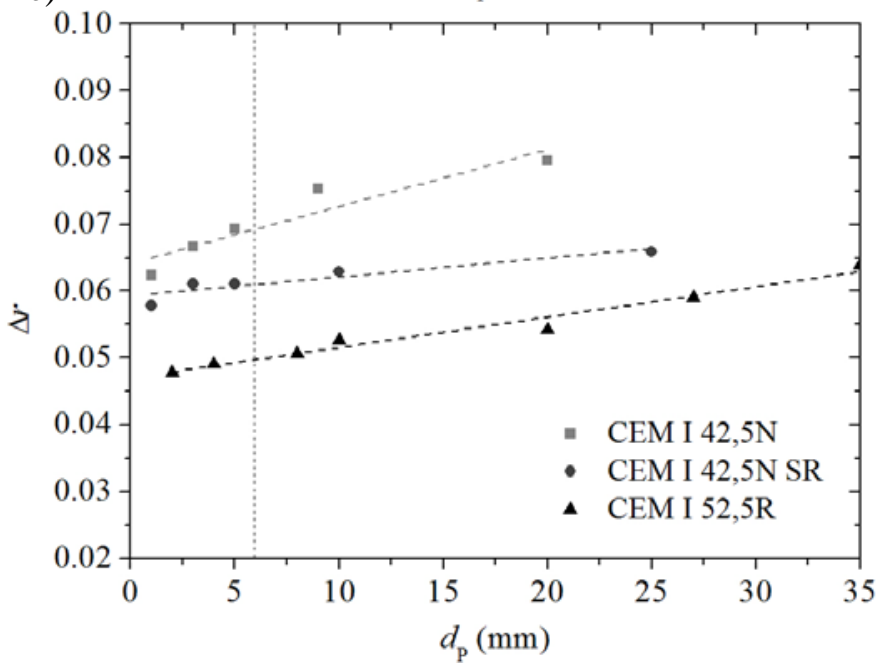

b)

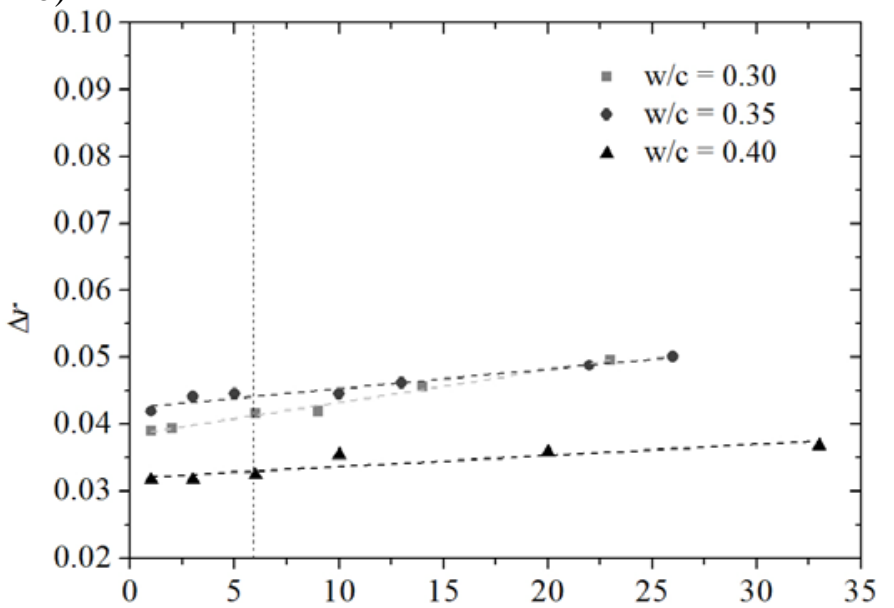

d)

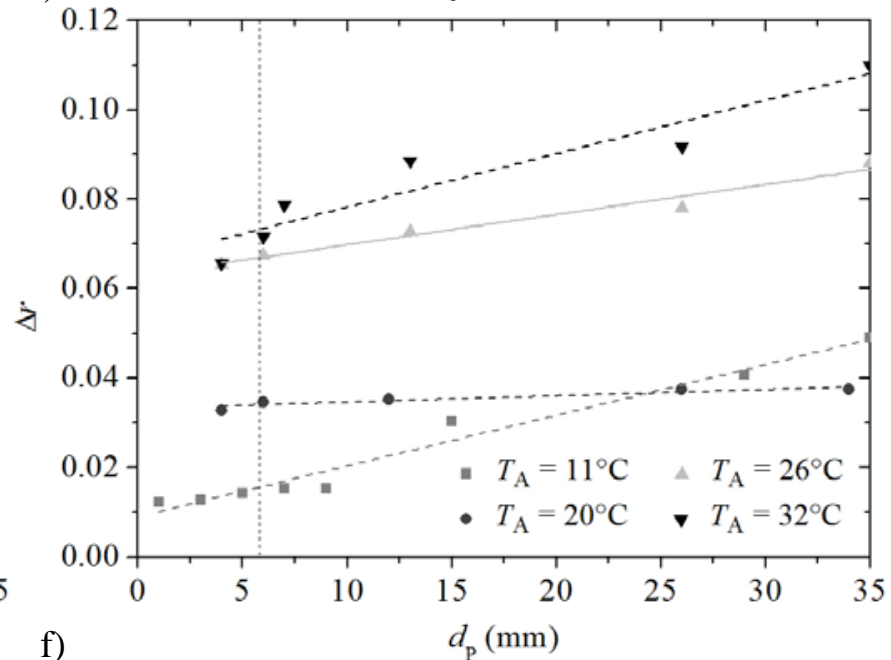


g)

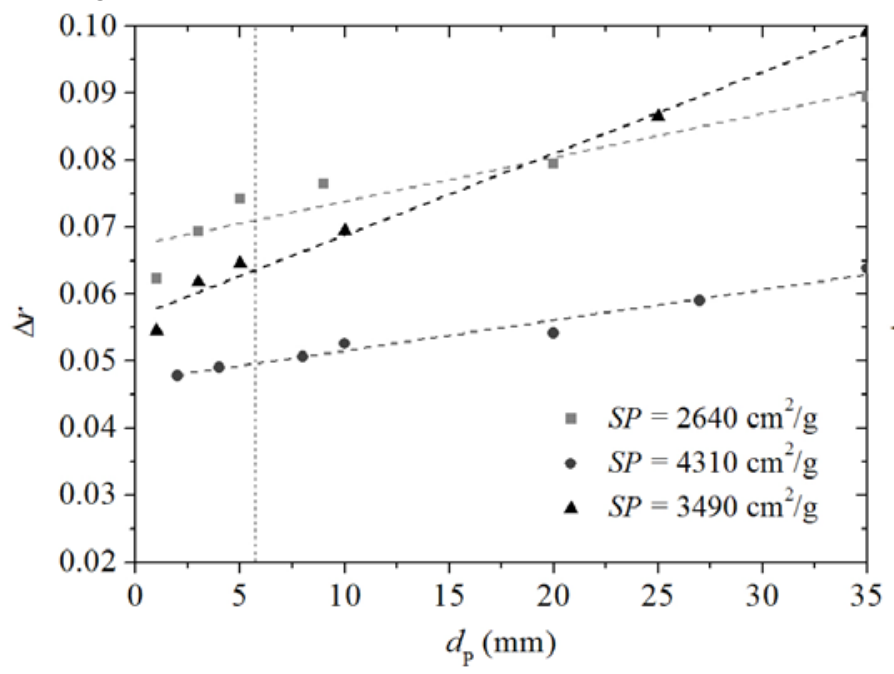

h)

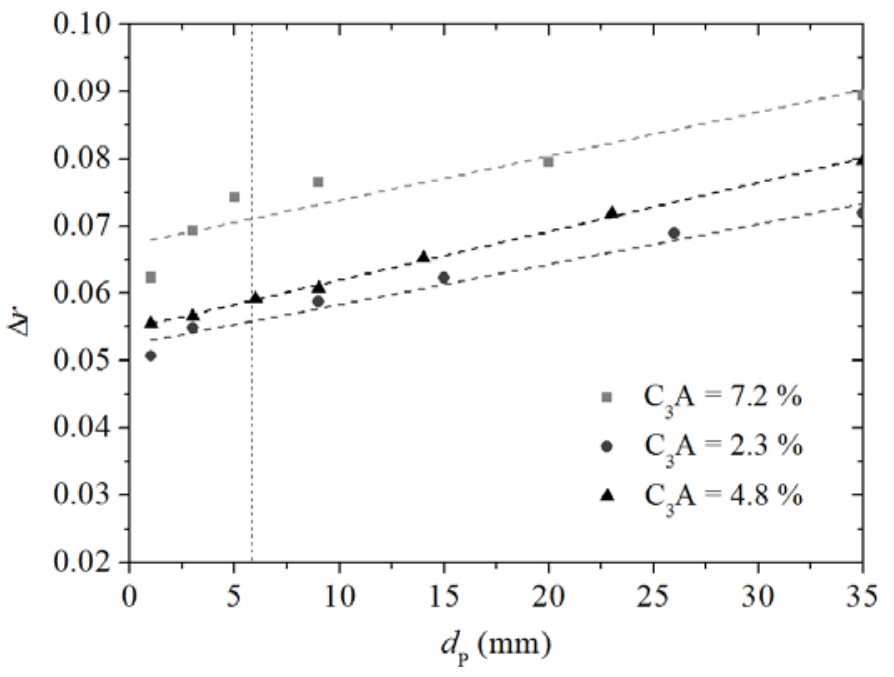

Fig. 6. Relationships between $\Delta r$ and $d_{\mathrm{P}}$ values influenced by; a,b) w/c ratio, c,d) curing temperature, e,f) cement type, g) cement fineness, h) $\mathrm{C}_{3} \mathrm{~A}$ amount.

\subsection{Simplified procedure to determine the initial and final setting time using USWR method}

On the basis of the results presented in Fig. 6, a simplified procedure for the determination of the complete $d_{\mathrm{P}}-t$ curve, including both initial and final setting time of a specific cement paste mixture is presented in Fig. 7. Since very similar $\mathrm{R}^{2}$ values were observed in the case of both linear and logarithmic relationships (refer to Table 3), the procedure is based on the linear $\Delta r-d_{\mathrm{P}}$ relationship due to its simplicity.

Consequently, two $d_{\mathrm{P}}\left(d_{\mathrm{PA}}, d_{\mathrm{PB}}\right)$ values (step 1) and corresponding $\Delta r\left(\Delta r_{\mathrm{A}}, \Delta r_{\mathrm{B}}\right)$ values (step 2) have to be determined at two different times $t_{\mathrm{A}}$ and $t_{\mathrm{B}}$ (see Fig. 7a) to establish a unique $\Delta r-d_{\mathrm{P}}$ relationship (step 3 , Fig. 7b) over the entire setting period. These points can be chosen arbitrary during the whole setting period of the cement paste (see Figs. 7a and $7 \mathrm{~b}$ ) which significantly fastens and simplifies the procedure.

Next, a value of a corresponding shear wave reflection coefficient (step 5) at a specific $d_{\mathrm{P}}$ point (step 4, for example initial (I) or/and final (F) setting time, the value $\Delta r_{0}$ when the penetration resistance starts to develop etc.) can be read from the $\Delta r-d_{\mathrm{p}}$ linear relationship (Fig. 7c). Finally, a time (step 7, initial setting time, final setting time, etc.) corresponding to the specific $\Delta r$ value (step 6) can be determined from the $\Delta r-t$ diagram (Fig. 7d). Using this simple procedure, different characteristic points, representing important milestones during the formation of structure process, can be easily indicated on the $\Delta r-t$ diagrams.

To practically demonstrate this procedure, examples of the determination of the initial $t_{\mathrm{I}}$ and final $t_{\mathrm{F}}$ setting times and corresponding $\Delta r_{\mathrm{I}}$ and $\Delta r_{\mathrm{F}}$ values are presented in Fig. 7. 
a)

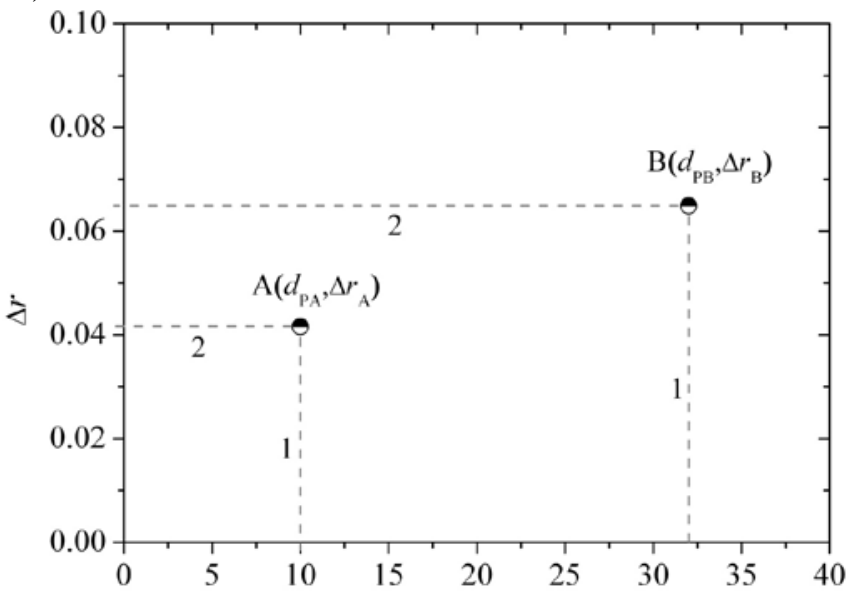

c)

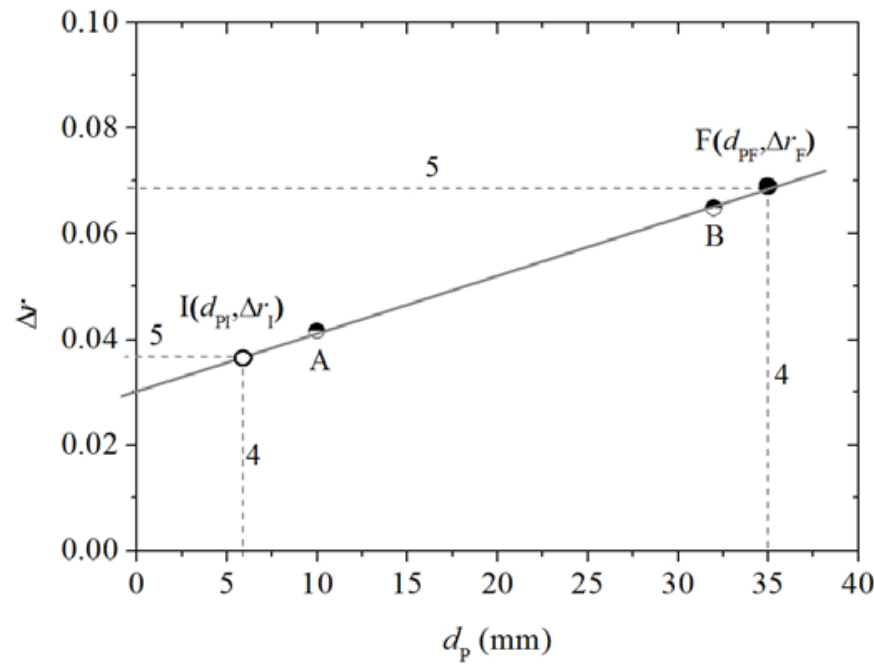

b)

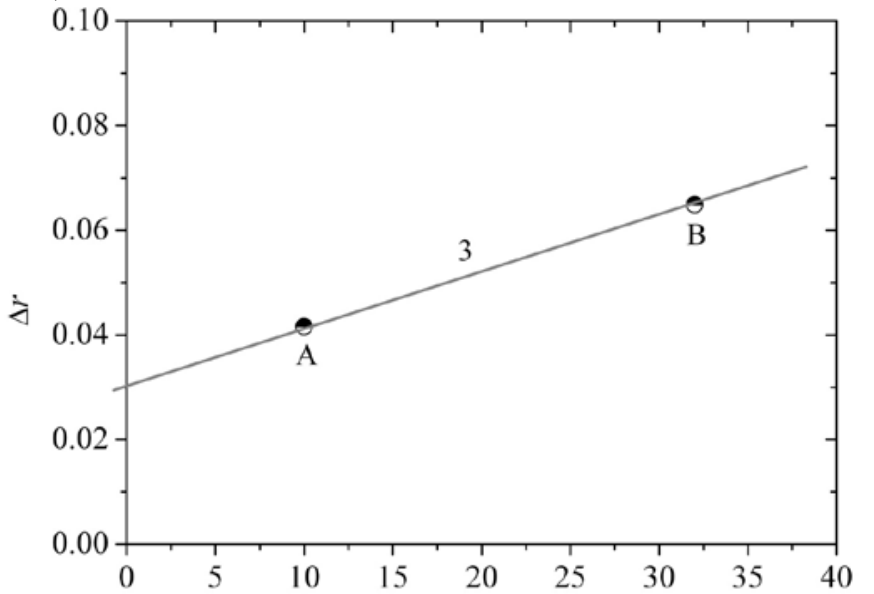

d)

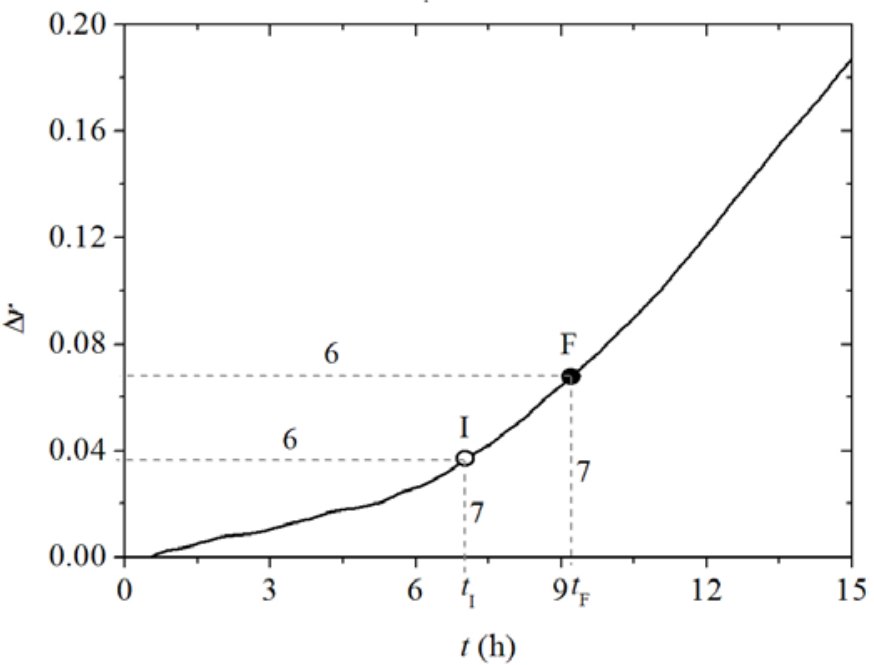

Fig. 7. Schematic representation of a simplified procedure for the determination of both initial and final setting time of a specific cement paste mixture.

\subsection{Accuracy of the initial and final setting time determination}

To analyze the accuracy of the proposed procedure, a technique was used which is schematically presented in Fig. 8. Since the method is based on two arbitrary Vicat points $d_{\mathrm{p}}$, different combinations between two points, presented in Fig. 6, were analyzed to determine the influence of the selection of the basic $d_{\mathrm{P}}$ points on the $t_{\mathrm{I}}$ and $t_{\mathrm{F}}$ results. Linear relationships between all pairs of $d_{\mathrm{P}}$ and corresponding $\Delta r$ points were established, resulting into several different $\Delta r-d_{\mathrm{P}}$ linear relationships for each cement paste mixture (see Fig. 8). 


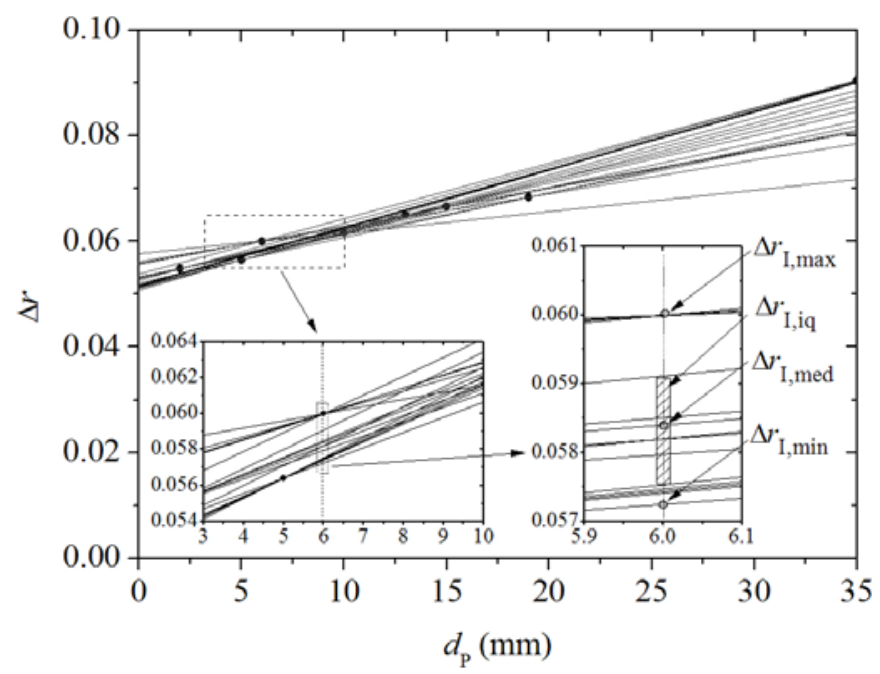

Fig. 8. Determination of the accuracy of the proposed procedure to estimate the initial and final setting times - schematic representation (initial setting time).

The values of $\Delta r_{\mathrm{I}}$ and $\Delta r_{\mathrm{F}}$ were determined for each linear relationship and descriptive statistics were used to analyze the data, which are summarized in Table 4. In the table, $n, \Delta r_{\mathrm{I}, \max }, \Delta r_{\mathrm{I}, \min }, \Delta r_{\mathrm{I}, \mathrm{med}}$, and $\Delta r_{\mathrm{I}, \mathrm{iq}}$ stand for the number of different relationships, maximum, minimum, median, and interquartile range of $\Delta r_{\mathrm{I}}$ values as indicated in Fig. 8. Similarly, $\Delta r_{\mathrm{F}, \max }, \Delta r_{\mathrm{F}, \min }, \Delta r_{\mathrm{F}, \text { med, }}$, and $\Delta r_{\mathrm{F} \text {,iq }}$ stand for maximum, minimum, median, and interquartile range of $\Delta r_{\mathrm{F}}$ values. It can be seen that all interquartile ranges are relatively small, indicating small dispersion that accompanies the median data.

Next, $t_{\mathrm{I}}$ and $t_{\mathrm{F}}$ setting times corresponding to all $\Delta r_{\mathrm{I}}$ and $\Delta r_{\mathrm{F}}$ values were determined and similar statistical analysis was performed to analyze the accuracy of the proposed procedure in estimating $t_{\mathrm{I}}$ and $t_{\mathrm{F}}$ setting times. It can be seen from Table 5 that in the case of $t_{\mathrm{I}}$ values, the $t_{\mathrm{I}, \mathrm{iq}}$ values, representing interquartile ranges are relatively small for all cement paste mixtures, indicating small influence of choosing different pairs of $d_{\mathrm{P}}$ values on the $t_{\mathrm{I}}$ results and thus high accuracy of the proposed method to determine initial setting times of cement pastes. A slightly higher $t_{\mathrm{F}, \text { iq }}$ values are observed in the case of $t_{\mathrm{F}}$ values, indicating slightly lower accuracy of the proposed method in estimating final setting times. In this case, maximum $t_{\mathrm{F}, \mathrm{iq}}$ was $58 \mathrm{~min}$. This variability can be reduced considerably if the second point is chosen at the time closer to the predicted final setting time. 
Table 4. Statistical analysis of the accuracy of the proposed procedure to estimate initial and final setting times $-\Delta r$ values.

\begin{tabular}{|c|c|c|c|c|c|c|c|c|c|c|}
\hline \multirow{2}{*}{\multicolumn{2}{|c|}{$\begin{array}{l}\text { mixture } \\
\text { label }\end{array}$}} & \multirow{2}{*}{$n$} & \multicolumn{4}{|c|}{$\Delta r_{I}(-)$} & \multicolumn{4}{|c|}{$\Delta r_{F}(-)$} \\
\hline & & & $\Delta r_{\mathrm{I}, \max }$ & $\Delta r_{\mathrm{I}, \min }$ & $\Delta r_{\text {I,med }}$ & $\Delta r_{\mathrm{I}, \mathrm{iq}}$ & $\Delta r_{\mathrm{I}, \max }$ & $\Delta r_{I, \min }$ & $\Delta r_{\text {I,med }}$ & $\Delta r_{\mathrm{I}, \mathrm{iq}}$ \\
\hline \multirow{6}{*}{ 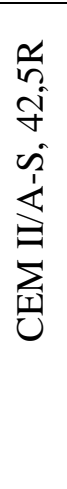 } & $\mathrm{w} / \mathrm{c}=0.30$ & 8 & 0.0416 & 0.0396 & 0.0414 & 0.00044 & 0.0617 & 0.0551 & 0.0563 & 0.00146 \\
\hline & $\mathrm{w} / \mathrm{c}=0.35$ & 12 & 0.0449 & 0.0433 & 0.0446 & 0.00110 & 0.0541 & 0.0445 & 0.0520 & 0.00178 \\
\hline & $\mathrm{w} / \mathrm{c}=0.40$ & 9 & 0.0338 & 0.0322 & 0.0324 & 0.00038 & 0.0548 & 0.0372 & 0.0394 & 0.00892 \\
\hline & $\begin{array}{l}\mathrm{w} / \mathrm{C}=0.50, \\
T_{\mathrm{A}}=20^{\circ} \mathrm{C}\end{array}$ & 6 & 0.0346 & 0.0331 & 0.0340 & 0.00134 & 0.0537 & 0.0485 & 0.0470 & 0.0099 \\
\hline & $\begin{array}{l}\mathrm{w} / \mathrm{C}=0.60 \\
T_{\mathrm{A}}=20^{\circ} \mathrm{C}\end{array}$ & 6 & 0.0552 & 0.0523 & 0.0541 & 0.00170 & 0.0967 & 0.0765 & 0.0886 & 0.01753 \\
\hline & $\mathrm{w} / \mathrm{c}=0.65$ & 9 & 0.0473 & 0.0447 & 0.0469 & 0.00219 & 0.0673 & 0.0592 & 0.0640 & 0.00242 \\
\hline \multirow{3}{*}{$\begin{array}{l}\text { ơ } \\
0 \\
11 \\
\frac{1}{3}\end{array}$} & CEM I 52,5R & 12 & 0.0503 & 0.0488 & 0.0498 & 0.00037 & 0.0767 & 0.0586 & 0.0633 & 0.00297 \\
\hline & CEM I 42,5N & 4 & 0.0741 & 0.0669 & 0.0695 & 0.00258 & 0.0931 & 0.0854 & 0.0904 & 0.00277 \\
\hline & CEM I 42,5N SR & 6 & 0.0619 & 0.0595 & 0.0614 & 0.00087 & 0.0771 & 0.0681 & 0.0693 & 0.00271 \\
\hline \multirow{3}{*}{$\begin{array}{l}\text { 웅 } \\
0 \\
11 \\
\frac{u}{3}\end{array}$} & $\begin{array}{l}\text { CEM I 52,5R } \\
S P=4310 \mathrm{~cm}^{2} / \mathrm{g}\end{array}$ & 12 & 0.0503 & 0.0488 & 0.0498 & 0.00037 & 0.0767 & 0.0586 & 0.0633 & 0.00297 \\
\hline & $\begin{array}{l}\text { CEM I } 42,5 \mathrm{~N} \\
S P=2640 \mathrm{~cm}^{2} / \mathrm{g} \\
\mathrm{C}_{3} \mathrm{~A}=7.2 \%\end{array}$ & 8 & 0.0758 & 0.0664 & 0.0729 & 0.00479 & 0.0931 & 0.0836 & 0.0895 & 0.00180 \\
\hline & $\begin{array}{l}\text { CEM I 42,5N SR } \\
\mathrm{C}_{3} \mathrm{~A}=2.3 \%\end{array}$ & 9 & 0.0573 & 0.0538 & 0.0566 & 0.00217 & 0.0789 & 0.0719 & 0.0742 & 0.00290 \\
\hline \multirow{3}{*}{$\begin{array}{l}\text { ○ी } \\
0 \\
11 \\
0 \\
3 \\
3\end{array}$} & $T_{\mathrm{A}}=32^{\circ} \mathrm{C}$ & 9 & 0.0781 & 0.0682 & 0.0717 & 0.00630 & 0.1443 & 0.0980 & 0.1098 & 0.02210 \\
\hline & $T A=26^{\circ} \mathrm{C}$ & 6 & 0.0675 & 0.0666 & 0.0673 & 0.00059 & 0.0909 & 0.0829 & 0.0882 & 0.00462 \\
\hline & $T_{\mathrm{A}}=11^{\circ} \mathrm{C}$ & 15 & 0.0187 & 0.0078 & 0.0155 & 0.00287 & 0.0807 & 0.0468 & 0.0491 & 0.01018 \\
\hline \multirow{3}{*}{$\begin{array}{l}8 \\
0 \\
0 \\
11 \\
\frac{0}{3}\end{array}$} & $T_{\mathrm{A}}=32^{\circ} \mathrm{C}$ & 15 & 0.0600 & 0.0573 & 0.0584 & 0.00250 & 0.0904 & 0.0716 & 0.0845 & 0.00715 \\
\hline & $T_{\mathrm{A}}=26^{\circ} \mathrm{C}$ & 9 & 0.0617 & 0.0591 & 0.0606 & 0.00165 & 0.0948 & 0.0895 & 0.0931 & 0.00237 \\
\hline & $T_{\mathrm{A}}=11^{\circ} \mathrm{C}$ & 10 & 0.0279 & 0.0218 & 0.0235 & 0.00236 & 0.0472 & 0.0373 & 0.0400 & 0.00625 \\
\hline & $S P=3490 \mathrm{~cm}^{2} / \mathrm{g}$ & 9 & 0.0657 & 0.0611 & 0.0652 & 0.00274 & 0.1109 & 0.0938 & 0.0992 & 0.00171 \\
\hline & $\mathrm{C}_{3} \mathrm{~A}=4.8 \%$ & 12 & 0.0592 & 0.0582 & 0.0590 & 0.00048 & 0.0840 & 0.0797 & 0.0810 & 0.00147 \\
\hline
\end{tabular}


Table 5. Statistical analysis of the accuracy of the proposed procedure to estimate initial and final setting times $-t_{\mathrm{I}}$ and $t_{\mathrm{F}}$ values.

\begin{tabular}{|c|c|c|c|c|c|c|c|c|c|c|}
\hline \multirow{2}{*}{\multicolumn{2}{|c|}{$\begin{array}{l}\text { mixture } \\
\text { label }\end{array}$}} & \multirow{2}{*}{$n$} & \multicolumn{4}{|c|}{$t_{I}(\mathbf{h})$} & \multicolumn{4}{|c|}{$t_{\mathrm{F}}(\mathrm{h})$} \\
\hline & & & $t_{I, \max }$ & $t_{I, \min }$ & $t_{\mathrm{I}, \mathrm{med}}$ & $t_{\mathrm{I}, \mathrm{iq}}(\mathrm{min})$ & $t_{I, \max }$ & $t_{\mathrm{I}, \min }$ & $t_{I, \text { med }}$ & $t_{\mathrm{I}, \mathrm{iq}}(\mathrm{min})$ \\
\hline \multirow{6}{*}{ 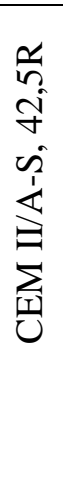 } & $\mathrm{w} / \mathrm{c}=0.30$ & 8 & 3.23 & 3.02 & 3.15 & 10.0 & 4.67 & 4.23 & 4.38 & 11.0 \\
\hline & $\mathrm{w} / \mathrm{c}=0.35$ & 12 & 4.73 & 4.41 & 4.70 & 19.0 & 5.63 & 4.68 & 5.45 & 6.6 \\
\hline & $\mathrm{w} / \mathrm{c}=0.40$ & 9 & 5.45 & 5.05 & 5.45 & 0.0 & 7.10 & 5.75 & 5.83 & 38.0 \\
\hline & $\begin{array}{l}\mathrm{w} / \mathrm{C}=0.50, \\
T_{\mathrm{A}}=20^{\circ} \mathrm{C}\end{array}$ & 6 & 6.82 & 6.81 & 6.81 & 0.5 & 9.33 & 8.59 & 8.90 & 15.1 \\
\hline & $\begin{array}{l}\mathrm{w} / \mathrm{C}=0.60 \\
T_{\mathrm{A}}=20^{\circ} \mathrm{C}\end{array}$ & 6 & 8.75 & 8.50 & 8.74 & 6.2 & 11.30 & 10.12 & 10.82 & 58.0 \\
\hline & $\mathrm{w} / \mathrm{c}=0.65$ & 9 & 8.93 & 8.83 & 8.88 & 6.0 & 10.47 & 9.88 & 10.22 & 13.0 \\
\hline \multirow{3}{*}{\begin{tabular}{l}
$o$ \\
\multirow{0}{0}{} \\
11 \\
0 \\
3 \\
3
\end{tabular}} & CEM I 52,5R & 12 & 3.75 & 3.73 & 3.75 & 0.0 & 4.63 & 4.08 & 4.23 & 4.7 \\
\hline & CEM I 42,5N & 4 & 5.98 & 5.45 & 5.22 & 15.1 & 6.57 & 6.32 & 6.51 & 6.0 \\
\hline & CEM I 42,5N SR & 6 & 7.38 & 7.17 & 7.28 & 5.2 & 8.88 & 8.10 & 8.20 & 18.0 \\
\hline \multirow{3}{*}{$\begin{array}{l}\text { 오․ } \\
\text { o } \\
11 \\
\frac{u}{3}\end{array}$} & $\begin{array}{l}\text { CEM I 52,5R } \\
S P=4310 \mathrm{~cm}^{2} / \mathrm{g}\end{array}$ & 12 & 3.10 & 2.98 & 3.06 & 2.0 & 4.52 & 3.75 & 3.99 & 8.5 \\
\hline & $\begin{array}{l}\text { CEM I } 42,5 \mathrm{~N} \\
S P=2640 \mathrm{~cm}^{2} / \mathrm{g} \\
\mathrm{C}_{3} \mathrm{~A}=7.2 \%\end{array}$ & 8 & 6.97 & 6.48 & 6.80 & 7.7 & 7.78 & 7.28 & 7.60 & 6.2 \\
\hline & $\begin{array}{l}\text { CEM I 42,5N SR } \\
\mathrm{C}_{3} \mathrm{~A}=2.3 \%\end{array}$ & 9 & 7.47 & 7.00 & 7.47 & 28.0 & 9.92 & 9.13 & 9.42 & 24.4 \\
\hline \multirow{3}{*}{$\begin{array}{l}\text { 우 } \\
0 \\
11 \\
0 \\
3\end{array}$} & $T_{\mathrm{A}}=32^{\circ} \mathrm{C}$ & 9 & 5.15 & 4.90 & 5.02 & 8.0 & 6.65 & 5.62 & 5.85 & 29.0 \\
\hline & $T A=26^{\circ} \mathrm{C}$ & 6 & 5.77 & 5.72 & 5.74 & 3.0 & 6.57 & 6.25 & 6.47 & 11.3 \\
\hline & $T_{\mathrm{A}}=11^{\circ} \mathrm{C}$ & 15 & 9.53 & 7.17 & 9.25 & 29.0 & 15.02 & 12.37 & 12.53 & 49.5 \\
\hline \multirow{3}{*}{$\begin{array}{l}8 \\
0 \\
0 \\
11 \\
\frac{0}{3}\end{array}$} & $T_{\mathrm{A}}=32^{\circ} \mathrm{C}$ & 15 & 5.62 & 5.52 & 5.53 & 5.0 & 6.68 & 5.98 & 6.47 & 16.0 \\
\hline & $T_{\mathrm{A}}=26^{\circ} \mathrm{C}$ & 9 & 6.98 & 6.92 & 6.95 & 0.0 & 8.42 & 8.25 & 8.35 & 6.0 \\
\hline & $T_{\mathrm{A}}=11^{\circ} \mathrm{C}$ & 10 & 10.53 & 9.70 & 9.95 & 26.0 & 13.80 & 12.38 & 12.75 & 54.2 \\
\hline- & $S P=3490 \mathrm{~cm}^{2} / \mathrm{g}$ & 9 & 5.12 & 4.90 & 5.08 & 7.0 & 6.90 & 6.27 & 6.48 & 4.0 \\
\hline- & $\mathrm{C}_{3} \mathrm{~A}=4.8 \%$ & 12 & 6.57 & 6.47 & 6.52 & 5.2 & 8.98 & 8.32 & 8.50 & 12.0 \\
\hline
\end{tabular}

\section{CONCLUSIONS}

In the context of materials and variables studied in the present work, the following main conclusions can be drawn from the obtained results:

o The change of the shear wave reflection coefficient $\Delta r$ was found to be very sensitive to the formation of the internal rigid structures in cement pastes far beyond the final setting time of the material. Significant differences in the evolution of the $\Delta r-t$ curves were noticed when cement pastes with various compositions were prepared and cured at different curing temperatures, indicating a possibility of the USWR method and apparatus to study the influence of the cement paste composition on the hydration process and formation of structure of the material. This further substantiates the results presented by other authors. 
o Using the presented USWR technique, a well known cross-over effect can be clearly observed and studied, proving that increased rate of the hydration caused by higher curing temperatures results into a weaker bond between the hydration products which hinders further hydration and formation of structure of cement based materials.

o Small increase in the $\Delta r$ coefficient was found at the very beginning of the hydration process, the value of which depends on the cement paste composition. Since this interesting effect was not observed by other researches, it is worth of further investigation.

o The initial and final setting times can't be defined by a specific value of the $\Delta r$ coefficient. The largest deviations were observed for different curing temperatures. However, a strong linear relationship between $\Delta r$ and $d_{\mathrm{P}}$ values was observed for all analyzed cement pastes during the entire setting process, indicating that the development of the $\Delta r$ coefficient in time clearly reflects the evolution of the (connected) solid phase in cement paste during this important hydration period. This relationship is not unique and is influenced by the cement paste composition and curing temperature.

o According to the linear $\Delta r-d_{\mathrm{P}}$ relationship, complete penetration resistance curve, including initial and final setting times, can be determined on the basis of the two $d_{\mathrm{P}}$ and corresponding $\Delta r$ values which can be chosen arbitrary during the entire setting period. This fastens and simplifies the procedure for determination of the initial and final setting time significantly, allows the measurements to be performed on a large number of specimens simultaneously, and eliminates the effects of technologist's inexperience and imprecision in determining the initial and final setting times of the material.

The results of this study show that presented NDT USWR method and apparatus can be effectively used to monitor the setting and hardening process of cementitious materials. Using this method, some interesting phenomena can be identified which may contribute to a better understanding of working principles of the hydration process and formation of structure of cement based materials. Four measuring heads operating simultaneously allow a large surface of the element to be tested at once, which is of great importance to withstand different kinetics of the setting process at various locations, originating from different ambient conditions and other influential parameters. The method is practical, low cost, and easily manageable and is therefore applicable in laboratory conditions as a research method as well as directly in situ.

\section{ACKNOWLEDGEMENT}

The authors gratefully acknowledge the financial support from Slovenian Research Agency as a part of the research project No. Z2-4069.

\section{REFERENCES}

[1] Zhang Y, Zhang W, She W, Ma L, Zhu W. Ultrasound monitoring of setting and hardening process of ultra-high performance cementitious materials. NDT E Int 2012; 47:177-184.

[2] Lee HK, Lee KM, Kim YH, Yim H, Bae DB. Ultrasonic in-situ monitoring of setting process of high-performance concrete. Cem Concr Res 2004; 34(4):631-640.

[3] Herb A. Indirekte Beobachtung des Erstarrens and Erhartens von Zementleim. Mortel und und Betton mittels Schallwellenausbreitung, University of Stuttgart, Stuttgart, Germany; 2003.

[4] Van der Widen NGB. Ultrasonic measurement for setting control of concrete. In: Reinhardt HW, editor. Testing during concrete construction, London: Chapman and Hall; 1990, p. 122-137.

[5] Trtnik G, Turk G, Kavčič F, Bokan Bosiljkov V. Possibilities of using the ultrasonic wave transmission method to estimate initial setting time of cement paste. Cem Concr Res 2008; 38(11):1336-1342.

[6] Trtnik G. The use of ultrasonic method to monitor the setting and hardening process of concrete. Ph.D. Thesis, University of Ljubljana, Ljubljana, Slovenia, 2009. 
[7] Robeyst N, Gruyaert E, Grosse CU, De Belie N. Monitoring the setting of concrete containing blast-furnace slag by measuring the ultrasonic p-wave velocity. Cem Concr Res 2008; 38(10):1169-1176.

[8] Khokhar MIA, Staquet S, Roziere E, Loukili A. Ultrasonic monitoring of setting of green concrete containing high cement substitution by mineral additions. NDTCE'09, Non-Destructive testing of Civil engineering Nantes, France; 2009.

[9] Ye G, Van Breugel K, Fraaij ALA. Experimental study and numerical simulation on the formation of microstructure in cementitious material at early age. Cem Concr Res 2003;33(2):233-239.

[10] Chotard T, Gimet-Brert N, Smith A, Fargeto D, Bonnet JP, Gault C. Application of ultrasonic testing to describe the hydration of calcium aluminate cement at the early age. Cem Concr Res 2001; 31(3):405-412.

[11] Stepišnik J, Lukač M, Kocuvan I. Measurement of cement hydration by ultrasonics. Am Ceram Soc Bull 1981;60(4):481-483.

[12] Valič MI. Hydration of cementitious materials by pulse echo USWR. Method, apparatus and application examples. Cem Concr Res 2000;30(10):1633-1640.

[13] Valič MI, Vuk T. A study of the influence of additives and admixtures on the hydration of cement with pulsed USWR method. KZLTET 2000;34(5):249-255.

[14] Sun Z, Ye G, Voigt T, Shah SP, Van Breugel K. Early age properties of portland cement pastes investigated with ultrasonic shear waves and numerical simulations. In: Weiss J, Kovler K, Marchand J, Mindess S, editors. Proceedings of the RILEM International of advances in concrete through science and engineering: CD-ROM, 2004, Evanston, USA.

[15] Voigt T, Ye G, Sun Z, Shah SP, Van Breugel K. Early age microstructure of Portland cement mortar investigated by ultrasonic shear waves and numerical simulation. Cem Concr Res 2005;35(5):858-866.

[16] Sun Z. Monitoring the early-age properties of cementitious materials with ultrasonic wave reflection method at macro-and micro-structural levels. PhD. Thesis, Northwestern University, Evanston, IL, USA, 2005.

[17] Van Breugel K. Simulation of Hydration and Formation of Structure of Hardening Cement-Based Materials - HYMOSTRUC. Ph.D Thesis, Delft University of Technology, Delft, Nederlands, 1997.

[18] Ye G, Van Breugel K, Fraaij ALA. Three dimensional microstructural analysis of numerically simulated cementitous materials. Cem Concr Res 2003;33(2):251-222.

[19] Valič MI, Stepišnik J, Gabrijelčič M, Vuk T. Setting times measurements of Portland cements with pulsed USWR method. KZLTET 1999;33(1-2):83-86.

[20] Voigt T, Sun Z, Shah SP. Health monitoring of early age concrete. $4^{\text {th }}$ international conference on concrete under severe conditions: environment and loading, Seoul, Korea; 2004.

[21] Ozturk T, Krogel O, Grubl P, Popovics JS. Improved ultrasonic wave reflection technique to monitor the setting of cement-based materials. NDT E Int 2006;39(4):258-263.

[22] Chung CW. Ultrasonic wave reflection measurements on stiffening and setting of cement paste. PhD Thesis, University of Illinois, Urbana-Champaign, Urbana, IL, USA; 2010.

[23] Chung CW, Popovics JS, Struble LJ. Early age stiffening of cement paste using ultrasonic wave reflection, in transmission from Liquid to Solid: Reexaming the behavior of concrete of early ages. ACI, Farmington Hills MI, SP-259-1; 2009, p. 7-16.

[24] Voigt T. The Application of an Ultrasonic Shear Wave Reflection Method for Nondestructive Testing of Cement-Based Materials at Early Ages. PhD. Thesis, University of Leipzig, Leipzig, Germany; 2004.

[25] Schindler AK, Dossey T, McCullough BF. Temperature control during construction to improve the long term performance of portland cement concrete pavements. Texas Department of 
Transportation, Research project No. 0-1700-2, The University of Texas at Austin, Austin, Tx, USA; 2002.

[26] Ye G. Experimental study and numerical simulation of the development of microstructure and permeability of cementitious materials. PhD Thesis, Delft University of Technology, Delft, Nederlands; 2003.

[27] Trtnik G, Valič MI, Kavčič F, Turk G. Comparison between two ultrasonic methods in their ability to monitor the setting process of cement pastes. Cem Concr Res 2009;39(10):876-882.

[28] Carino NJ, 1991, The Maturity method. In Handook on Nondestructive Testing of Concrete, Carino NJ and Malhotra M (eds.), CRC Press: Boca raton, Florida, pp. 101-146.

[29] Wade SA, Schindler AK, BBarnes RW, Nixon JM, Evaluation of the Maturity Method to estimate Concrete Strength, Research Report, ALDOT Research Project 930-590, Highway research center, Department of Civil Engineering, Auburn University, Auburn, AL, 2006.

[30] Carino NJ, Lew HS, The maturity method: from theory to application, In Chang PC (ed.): Proceedings of the 2001 Structures Congress and Exposition, Washington DC, 2001, pp. 1.19.

[31] Elsageer MA, Millard SG, Barnett SJ, Strength development of concrete containing coal fly ash under different curing temperature conditions, 2009 World of Coal Ash (WOCA) Conference, Lexington, KY, 2009.

[32] Trtnik G, Kavcic F, Turk G, The use of artificial neural networks in adiabatic curves modeling, Automation in Construction, 18 (1) (2008) 10-15

[33] Verbeck GJ, Helmuth RH, Structures and Physical Properties of Cement Paste, Proceedings of the Fifth International Symposium on the Chemistry of Cement, Tokyo, 1968, pp.1-32.

[34] Valič MI, Stepišnik J, An ultrasonic shear wave apparatus and its applications in materials research, 34th International Conference on Microelectronics, Devices and Materials, Rogaška Slatina, Slovenia 1998. 